\title{
INTERANNUAL VARIABILITY OF THE TROPICAL ATLANTIC INDEPENDENT OF AND ASSOCIATED WITH ENSO: PART II. THE SOUTH TROPICAL ATLANTIC
}

\author{
ITSUKI C. HANDOH, ${ }^{\mathrm{a}, *}$ GRANT R. BIGG, ${ }^{\mathrm{b}}$ ADRIAN J. MATTHEWS ${ }^{\mathrm{a}, \mathrm{c}}$ and DAVID P. STEVENS \\ a School of Environmental Sciences, University of East Anglia, Norwich, UK \\ ${ }^{\mathrm{b}}$ Department of Geography, University of Sheffield, Sheffield, UK \\ c School of Mathematics, University of East Anglia, Norwich, UK
}

Received 26 April 2005

Revised 8 February 2006

Accepted 3 March 2006

\begin{abstract}
Two dominant ocean-atmosphere modes of variability on interannual timescales were defined in part I of this work, namely, the North Tropical Atlantic (NTA) and South Tropical Atlantic (STA) modes. In this paper we focus on the STA mode that covers the equatorial and sub-tropical South Atlantic. We show that STA events occurring in conjunction with ENSO have a preference for the southern summer season and seem to be forced by an atmospheric wave train emanating from the central tropical Pacific and travelling via South America, in addition to the more direct ENSO-induced change in the Walker Circulation. They are lagged by one season from the peak of ENSO. These events show little evidence for other-than-localised coupled ocean-atmosphere interaction.

In contrast, STA events occurring in the absence of ENSO favour the southern winter season. They appear to be triggered by a Southern Hemisphere wave train emanating from the Pacific sector, and then exhibit features of a selfsustaining climate mode in the tropical Atlantic. The southward shift of the inter tropical convergence zone that occurs during the warm phase of such an event triggers an extra tropical wave train that propagates downstream in the Southern Hemisphere. We present a unified view of the NTA and STA modes through our observational analysis of the interannual tropical Atlantic variability. Copyright (C) 2006 Royal Meteorological Society.
\end{abstract}

KEY WORDS: tropical Atlantic variability; ENSO; ocean-atmosphere interaction; teleconnections; Equatorial Atlantic Oscillation

\section{INTRODUCTION}

Co-variability of sea surface temperature (SST) and zonal wind stress $\left(\tau_{x}\right)$ is indicative of ocean-atmosphere coupled modes. The relative importance of internal and remotely forced variability in the tropical Atlantic has been intensively debated (e.g. Servain et al., 1982; Carton and Huang, 1994; Curtis and Hastenrath, 1995; Klein et al., 1999; Huang et al., 2002; Liu et al., 2004; Xie and Carton, 2004). In the companion paper (Handoh et al., 2006), we have shown through singular value decomposition (SVD) analysis that there are two dominant modes in the tropical Atlantic: the North Tropical Atlantic (NTA) and South Tropical Atlantic (STA) modes. Each mode was sub-divided into two types of events: ones associated with ENSO (ENSO-associated events) and others independent of ENSO (ENSO-independent events). The causal mechanism of warm/cold events in the NTA appears to be a Pacific-North America (PNA) like wave train emanating from the Pacific basin, with a passive oceanic response to the induced changes in the overlying trade; local wind-evaporationSST (WES) feedback (Xie and Philander, 1994) was not confirmed. This wave train appears to be the crucial

\footnotetext{
* Correspondence to: Dr Itsuki C. Handoh, Department of Applied Mathematics, The University of Sheffield, The Hicks Building, Hounsfield Road, Sheffield S3 7RH, UK; e-mail: i.handoh@shef.ac.uk
} 
mechanism for both ENSO-associated and ENSO-independent events; the latter cannot be entirely generated within the NTA sector. Hereafter we focus on the STA (second) mode.

The equatorial Atlantic exhibits a quasi-biennial oscillation of SST anomalies (Tourre et al., 1999; Tseng and Mechoso, 2001). In the STA, SST anomalies co-vary with those of the surface wind and convection on this same timescale (Ruiz-Barradas et al., 2000). The patterns of the SST and surface wind anomalies are reminiscent of ENSO in the Pacific. The heat flux anomalies associated with the equatorial events tend to locally damp the initial SST anomalies over the eastern Atlantic basin (Sutton et al., 2000; Mo and Häkkinen, 2001). In fact, what maintains the equatorial SST anomalies is the Bjerknes (1969) feedback that is characterised by the westward propagation of coupled ocean-atmosphere anomalies. However, from the theory of unstable ocean-atmosphere coupled modes in tropical basins, self-sustaining warm-cold cycles can exhibit both westward and eastward propagation (Hirst, 1988). In a modelling study, CabosNarvaez et al. (2002) showed that there are two ways in which SST anomalies can be developed over the Gulf of Guinea: one is an eastward propagation in response to the atmospheric anomalies and the other is as a standing oscillation.

Handoh and Bigg (2000) proposed that the equatorial Atlantic could exhibit a self-sustaining climate mode. The mode was hypothesised to involve equatorial and off-equatorial wave dynamics: an oceanic downwelling Kelvin wave, excited by equatorial westerly anomalies at the western Atlantic, propagates eastwards; this is reflected from the African coast and becomes a slow westward propagating wave of warm SST anomalies on and off the equator. The westward propagation was only one-third the expected phase speed of an oceanic Rossby wave along the equator. This suggests ocean-atmosphere interaction through SST, surface wind, and atmospheric convective anomalies. Handoh and Bigg (2000) therefore called the westward propagating wave a coupled-mode wave. The arrival of the westward propagating, convective anomalies and their associated wind stress anomalies at the western equatorial Atlantic were hypothesised to force an eastward-propagating oceanic upwelling Kelvin wave to cross back to Africa, followed by a slow westward propagating wave of negative SST anomalies. The overall dynamics of the equatorial Atlantic climate variability is consistent with the fundamental unstable mode of the tropical basin of Hirst's $(1986,1988)$ model II. This warm-cold cycle can be repeated a number of times, and is a self-sustaining oscillation. The periodicity of the oscillation over the equator is in good agreement with that of the quasi-biennial oscillation of the equatorial Atlantic (Tseng and Mechoso, 2001), although propagating events of such equatorial anomalies seem to be very rare (Handoh and Bigg, 2000). This Equatorial Atlantic Oscillation (EAO) includes off-equatorial anomalies over the STA. A model experiment of the equatorial Atlantic coupled mode was studied by Zebiak (1993). He showed that the oscillation cannot be self-sustained over a decade or two, in contrast to Hirst (1986, 1988), probably because this unstable mode prefers the basin size of the tropical Pacific to that of the tropical Atlantic.

However, a few cases of eastward propagating SST anomalies in the tropical Atlantic can be found in the events of 1983-1984 and 1997-1998, which seem to have been associated with the Pacific El Niño events of 1982-1983 (Philander, 1986; Delecluse et al., 1994) and 1997-1998 (Latif and Grötzner, 2000), respectively. The former displayed some ocean-atmosphere interaction (see e.g. Horel et al., 1986). Latif and Grötzner (2000) studied an 'EAO'. They showed that ENSO-associated equatorial events in the Atlantic display slow eastward-propagating anomalies (Philander, 1986), in contrast to a slow westward-propagating co-variability of SST and atmospheric anomalies during the type of event that is independent from ENSO (Handoh and Bigg, 2000). Extrapolating from the dynamics of Hirst's (1988) unstable mode, however, external forcing such as ENSO does not necessarily determine the direction of propagation of the coupled equatorial Atlantic anomalies; rather, the eastward-propagating SST anomalies may be just a passive oceanic response to the ENSO-induced change in the overlying trades (Latif and Grötzner, 2000).

A brief description of the STA climate mode is presented in Section 2. Details of the methodology were given by Handoh et al. (2006). Section 3 summarises and discuss the composite analysis of selected climate variables and the global significance of ENSO-associated and ENSO-independent events. The implications of these analyses are considered in Section 4, and we will discuss the possibility of a purely internal climate oscillation of the equatorial Atlantic, pulling together this work with that of Handoh et al. (2006). 


\section{DATA AND ANALYSIS}

\subsection{Data}

We used monthly mean SST, surface zonal $\left(\tau_{x}\right)$ and meridional $\left(\tau_{y}\right)$ wind stresses, and sea-level pressure (SLP) in order to examine the surface structure of the climate variability, and zonal and meridional wind components, horizontal divergence and streamfunction at three different pressure levels: 1000, 850, and $200 \mathrm{hpa}$. The pressure coordinate vertical velocity at $500 \mathrm{hpa}$ is also used. SST was from the UK Met Office Global Ice and Sea Surface Temperature (GISST) dataset and the remaining variables were from the NCEP-NCAR re-analysis products (Kistler et al., 2001). We used the period from January 1948 to December 1999.

We have shorter sets of monthly data of outgoing longwave radiation (OLR), surface shortwave radiation flux, surface longwave radiation flux, and latent heat flux. OLR was used as a proxy for deep tropical convection (Liebmann and Smith, 1996), for the period 1974-1999. The latent heat flux was calculated using the TOGA-COARE bulk flux algorithm (Fairall et al., 1996) with SST and surface atmospheric datasets as input parameters from July 1983 to June 1999. We employed the International Satellite Cloud Climatology Project (ISCCP) D2 monthly data in order to calculate surface shortwave and longwave radiation fluxes. The algorithms for surface shortwave and longwave radiation estimates are adapted from Bishop and Rossow (1991) and Gupta et al. (1992), respectively (and references therein). Owing to the limited vertical pressure levels of the TIROS Operational Vertical Sounder (TOVS) data in ISCCP D2 products, we used linear interpolation (Darnell et al., 1983) to estimate TOVS-derived temperature and water burden at each $50 \mathrm{hpa}$ interval. SST, and heat flux data were interpolated onto a $2.5^{\circ} \times 2.5^{\circ}$ grid, to match the spatial resolution of the NCAR-NCEP re-analysis datasets.

We removed the long-term linear trend and annual cycle from each data set, and then applied an order 12 Butterworth filter to derive inter-annual fluctuations in the 12-72 month band. Owing to the filtering effect, the first and last 12 months of data were removed.

\subsection{Composite analysis}

We have discussed the SVD analysis of these data and the two leading modes it produces in Handoh et al. (2006). Note that the outcome of SVD analysis of SST and $\tau_{x}$ will be somewhat different from previous studies, which used empirical orthogonal function analysis (or equivalent analysis) of SST anomalies (e.g. Enfield and Mayer, 1997; Sutton et al., 2000). Both methods have different merits, but the SVD analysis provides more information about possible coupled ocean-atmosphere modes. Here we concentrate on the second mode, the STA mode, which described $30 \%$ of the variance in co-variability of SST and $\tau_{x}$. This inevitably involves some repeat of material.

The spatial structure of the STA mode (Figure 1(a) and (b)) covers both the equatorial Atlantic and STA. It displays the largest, organised signals in both SST and $\tau_{x}$ anomalies over the STA (Figure 1(a) and (b), respectively), consistent with the STA pattern found in previous work (Enfield and Mayer, 1997; Dommenget and Latif, 2000; Mo and Häkkinen, 2001). However, this spatial organisation of the STA pattern may be a manifestation of equatorial and sub-tropical modes combining (Florenchie et al., 2004; Huang, 2004; Wu et al., 2004). We would like to stress, however, that neither (rotated) empirical orthogonal function analysis of SST anomalies, nor SVD analysis of SST and surface zonal wind stress anomalies, picks up the so-called Benguela mode, unless the analysis is geographically restricted.

In addition, modest, isolated anomalies exist over the eastern tropical North Atlantic basin. The largest positive $\tau_{x}$ anomalies are located west of those of SST, with weak, negative anomalies of $\tau_{x}$ to the east of the SST anomaly maximum. This pattern over the equatorial region was found in previous work (Zebiak, 1993; Handoh and Bigg, 2000; Ruiz-Barradas et al., 2000; Tseng and Mechoso, 2001).

ENSO-associated events can be distinguished from ENSO-independent events, in the manner presented by Handoh et al. (2006). The coupling index defined there, A2, is weakly correlated with the tropical Pacific through a range of leads and lags, but it correlates well with the equatorial Atlantic index, ATL3 $(r=0.85$, $p<0.05)$ without lags. The maximum correlation with ENSO occurs with a 1-month lag $(r=0.24, p<0.05)$. 
(a)

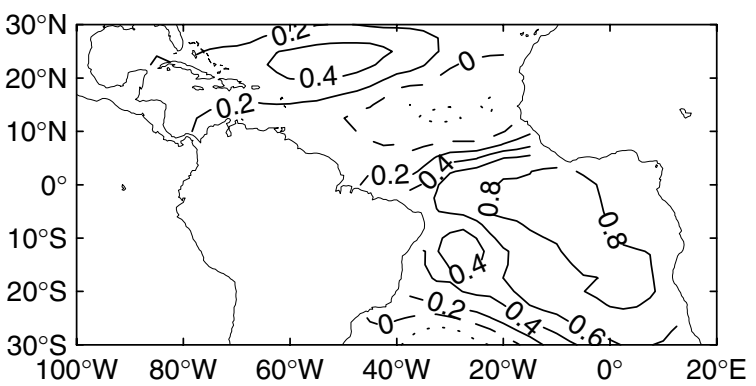

(b)

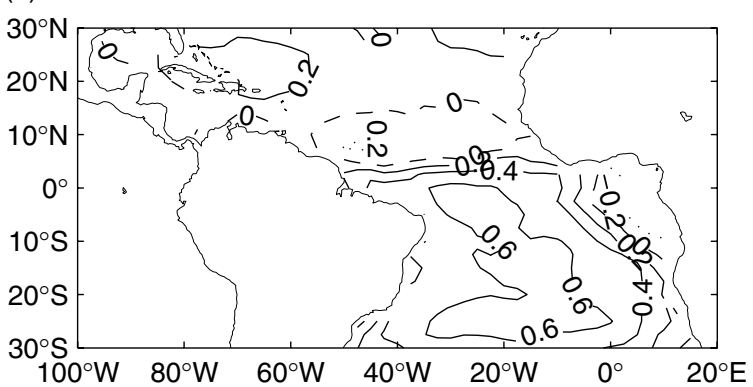

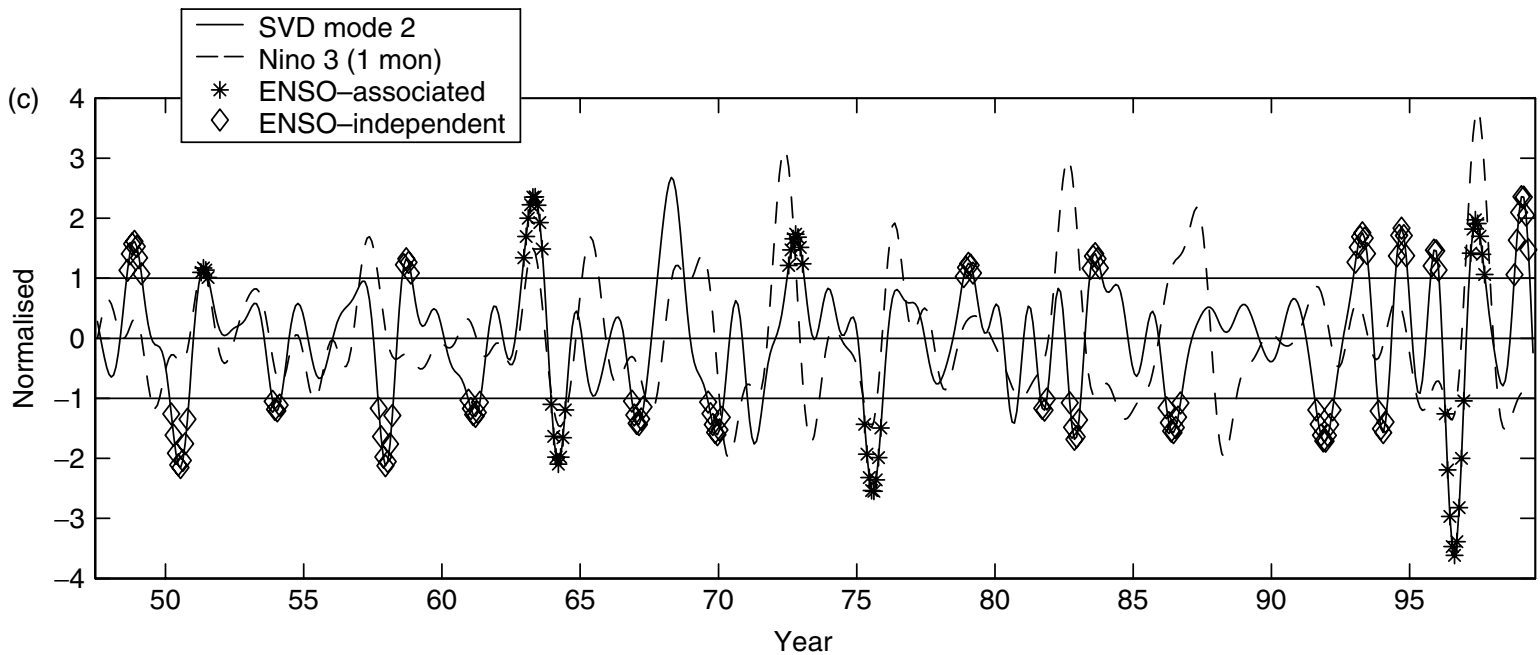

Figure 1. Anomaly correlation maps of SVD 2 over the Atlantic domain $\left(30^{\circ} \mathrm{S}-30^{\circ} \mathrm{N}\right)$ : (a) SST anomaly; (b) zonal wind stress anomaly. Contour interval is 0.2. Negative contours are dotted, and zero contour is omitted. (c) Time series of A2 (solid line) and NINO3 (dashed line, lagged by 1 month). Months included in the ENSO-associated (ENSO-independent) composites are indicated by stars (diamonds). Reproduced from Handoh et al. (2006)

This indicates that our STA mode is essentially independent from ENSO. However, some events seem to be induced by ENSO signals, and the sign of the correlation coefficient could vary with season (Saravanan and Chang, 2000). The lag time of 1 month is shorter than that previously reported between the tropical Pacific and STA SST anomalies (4 months; Enfield and Mayer 1997) and between the tropical Pacific and equatorial Atlantic ( $\sim 6$ months; Latif and Grötzner, 2000), but consistent with the surface wind anomalies (1 month; Enfield and Mayer, 1997). We will examine this further in Section 3.4. The occurrence of ENSO-associated and ENSO-independent events shows a preference in the seasonal cycle for October-March and April-July, respectively; they are approximately out of phase.

Composites for the STA mode were constructed by selecting months in which A2 $>1$ (warm events) and those in which A2 $<-1$ (cold events). Those are then further sub-divided into events that were classed as occurring in conjunction with ENSO, called ENSO-associated events, when the 1-month lagged NINO3 index was above 1 for the warm events and below -1 for the cold events. The remaining selected months were classed as ENSO-independent events, with no associated ENSO signal (Figure 1(c)). Warm and cold event composites (both events) had similar patterns, but with opposite sign, and are summarised here as an average of the warm minus cold pattern. This linearity occurs because in our composite method the primary criterion is the tropical climate variability (A2). Previous studies report that the global response to ENSO signals is essentially non-linear (e.g. Pozo-Vazquez et al., 2001; Wu and Hsieh, 2004; Mariotti et al., 2005), but ENSO here is used as a secondary criterion, reducing the importance of its non-linearity. Note that because of the short lag, and weak correlation between ENSO and STA, the drawback of this statistical analysis is that a few 
events that were considered to be induced by ENSO (e.g. 1983-1984; Philander, 1986) are now classified as ENSO-independent events (Figure 1(c)).

A re-sampling technique was used to examine the statistical significance of the composite maps. Following Matthews and Kiladis (1999), 10000 paired synthetic time-series for A2 and the 1-month lagged NINO3 index were created, with the same auto-correlation and cross-correlation characteristics as the original time-series. The local significance of the composite patterns at each grid point was then tested at the $95 \%$ level against the distribution function calculated from the synthetic time-series.

Since the seasonal phase-locking for ENSO-associated and -independent events is relatively weak (Handoh et al., 2006), we have also constructed lag composites in order to examine the origin and evolution of warm and cold events. For each warm (cold) event, the month with a temporal maximum (minimum) of A2 is defined as month 0 . Then, 3 -month means centred over months $-9,-6,-3,0,+3,+6,+9$ were calculated in order to compute a series of lag/lead composite maps. It should be stressed that the mean atmospheric state could vary significantly over the period for which the peaks of an ENSO-associated or -independent event could last. This will affect parts of the global atmospheric response to the tropical SST anomalies. However, there is still a robust part of the response that does not depend sensitively on the season. Our re-sampling technique was used to examine the statistical significance of the composited anomalies, and identified this robust response (see Section 3.4).

\section{RESULTS}

\subsection{Sea surface temperature, wind stress and convection}

Global SST and wind stress anomaly vectors for the STA mode occurring in conjunction with ENSO are shown in Figure 2(a). Positive SST anomalies between 0.1 and $0.4^{\circ} \mathrm{C}$ and northwesterly wind stress anomalies cover the equatorial and South Tropical Atlantic. This is accompanied by a band of weaker positive SST anomalies over the tropical North Atlantic, which is not seen in the composite map of Mo and Häkkinen (2001). In our analysis the STA mode contains SST anomalies in the equatorial and off-equatorial $\left(15-30^{\circ} \mathrm{S}\right)$ regions, and that the former co-exists with weaker wind anomalies than does the latter. Part of this is consistent with previous work, which suggests that the STA consists of a few modes (Huang, 2004; Wu et al., 2004). Negative SST anomalies are found in the extra-tropical South Atlantic, with southeasterly wind stress anomalies extending from the mid-latitudes. Together with the sub-tropical westerly anomalies, they form a cyclonic anomaly.

Other significant positive SST anomalies are found in the Indian Ocean, and more markedly in the centraleastern tropical Pacific, consistent with an El Niño. Negative SST anomalies are present in the South Pacific over the sub-tropical latitudes, but the spatial extent is much smaller than for mode 1 (Handoh et al., 2006), and so is the North Pacific counterpart. Positive SST anomalies are also found along the west coast of North America.

Similar to the ENSO-associated events, ENSO-independent events show significant year-round SST anomalies over the STA (Figure 2(b)). Again, the STA exhibits both equatorial and off-equatorial peaks in SST anomalies. These are associated with northwesterly wind stress anomalies. To some extent, the ENSOindependent warm events show northerly cross-equatorial winds, and are similar to those of Ruiz-Barradas et al. (2000). There are no significant and organised SST anomalies in other ocean basins.

Composites of OLR were constructed using the data from 1974 to 1999. Although over this period there were only 1 warm and 2 cold ENSO-associated events, our re-sampling technique confirmed the statistical significance of the composite maps. However, it should be stressed that our ENSO-associated results for the OLR analysis may be strictly applicable only to 1995-2000, because there is inter-decadal variability in the ENSO teleconnection (Compo et al., 2001; Diaz et al., 2001).

Consistent with the positive SST anomalies over the equatorial central and eastern Pacific, deep convection was enhanced (negative OLR anomalies) in these regions and suppressed over Indonesia (Figure 3(a)) during the ENSO-associated events. This was also found for the NTA mode (mode 1; Figure 5(a) in Handoh et al., 2006); it is essentially the El Niño signal. Over the Atlantic sector, convection in the intertropical convergence zone (ITCZ) and over the Amazon was suppressed. As with the NTA mode (Handoh et al., 2006), the latter is 
(a)

$\overrightarrow{0.01}$

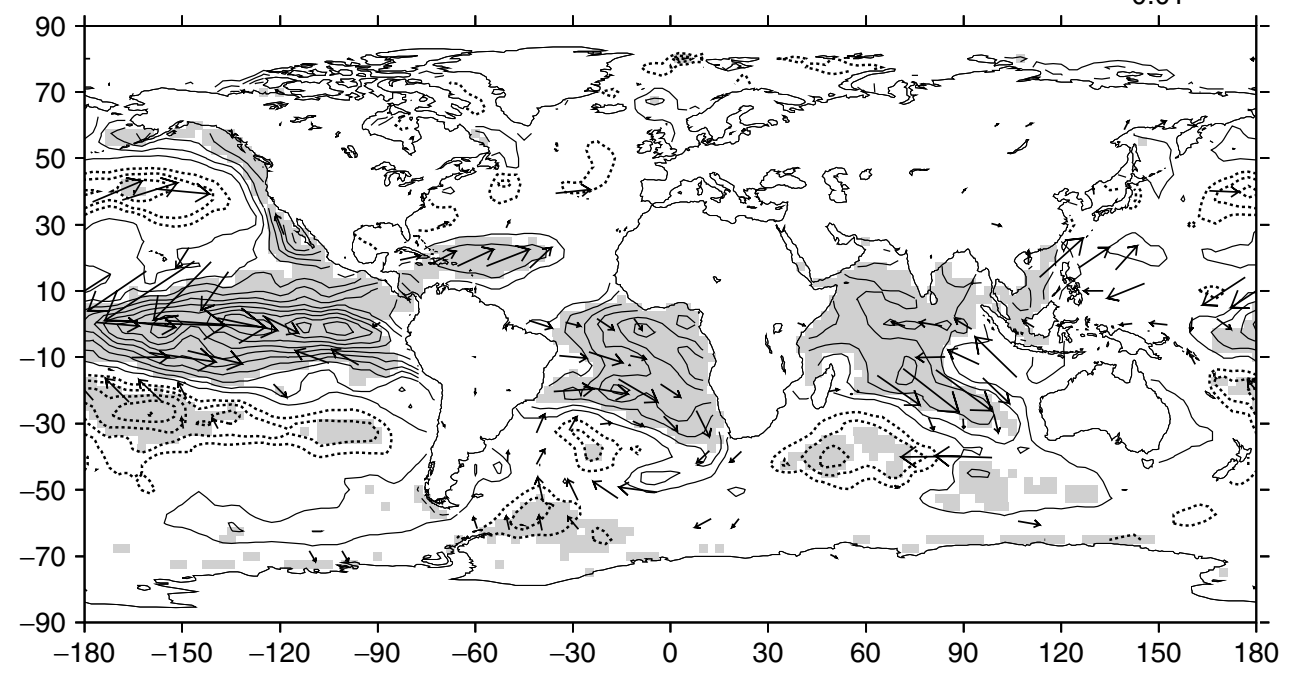

(b)

$\overrightarrow{0.01}$

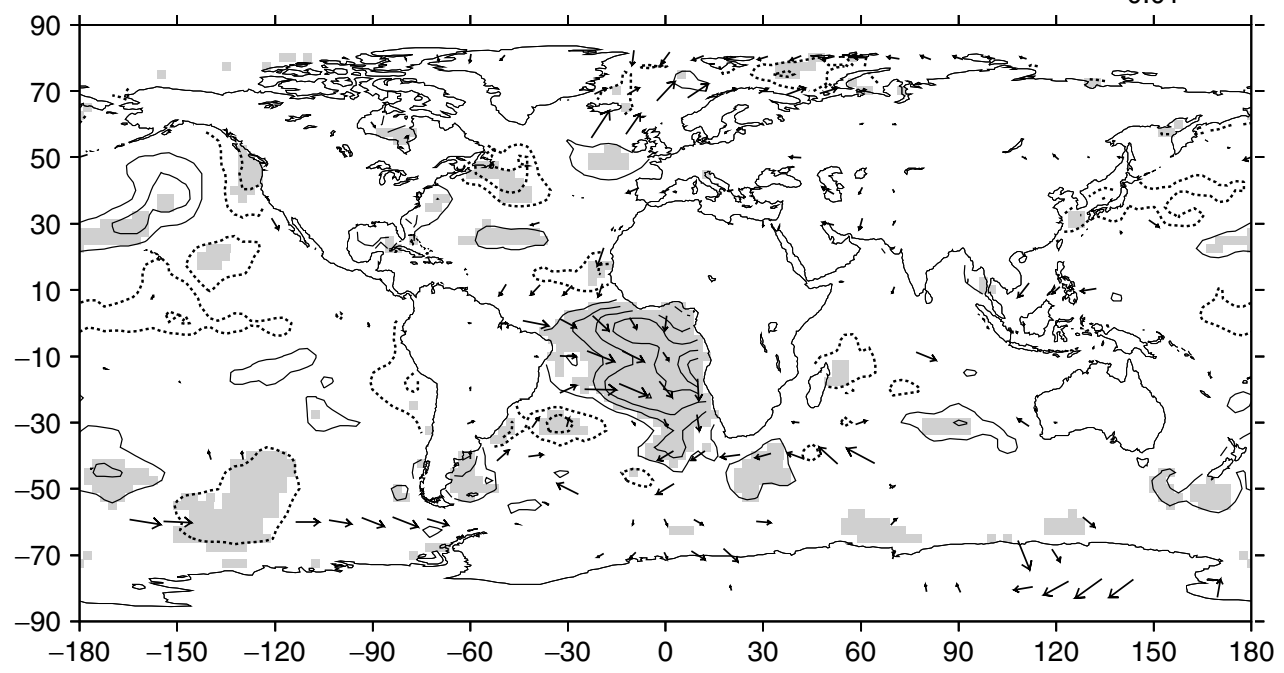

Figure 2. Global composite anomaly maps for mode 2 (average of warm minus cold events) of SST anomalies and wind stress vectors, (a) ENSO-associated events, (b) ENSO-independent events. SST contour interval is $0.1{ }^{\circ} \mathrm{C}$, and anomalies significant at the $95 \%$ level are shaded. Positive and negative anomalies are contoured by solid, and dotted lines, respectively. The zero contour is omitted. The reference surface wind stress vector is $0.01 \mathrm{~N} / \mathrm{m}^{2}$, and vectors are only plotted (every $10^{\circ}$ ) where either the $x$ or $y$-component is significant

indicative of suppressed convective rainfall, which suggests that in these cases the link between the Amazonian rainfall and tropical Atlantic warm events is induced by ENSO. However, the spatial pattern is different from that of the NTA mode (Handoh et al., 2006). Negative OLR anomalies over the northern sub-tropical Atlantic indicate an enhancement of low-level stratocumulus that may be associated with a decrease in the subsiding branch of the Hadley Cell, confirmed by diagnosis of vertical velocity anomalies (not shown). Even though there are positive SST anomalies above $0.5^{\circ} \mathrm{C}$ over much of the equatorial and South Tropical Atlantic, there are no negative OLR anomalies over this region, implying that the convective anomalies during these events are controlled by the Pacific region. Thus, although there is a tendency for the ITCZ to shift south, since the tropical north and south Atlantic are warm, the cross equatorial SST gradient is small and the ITCZ tends to 

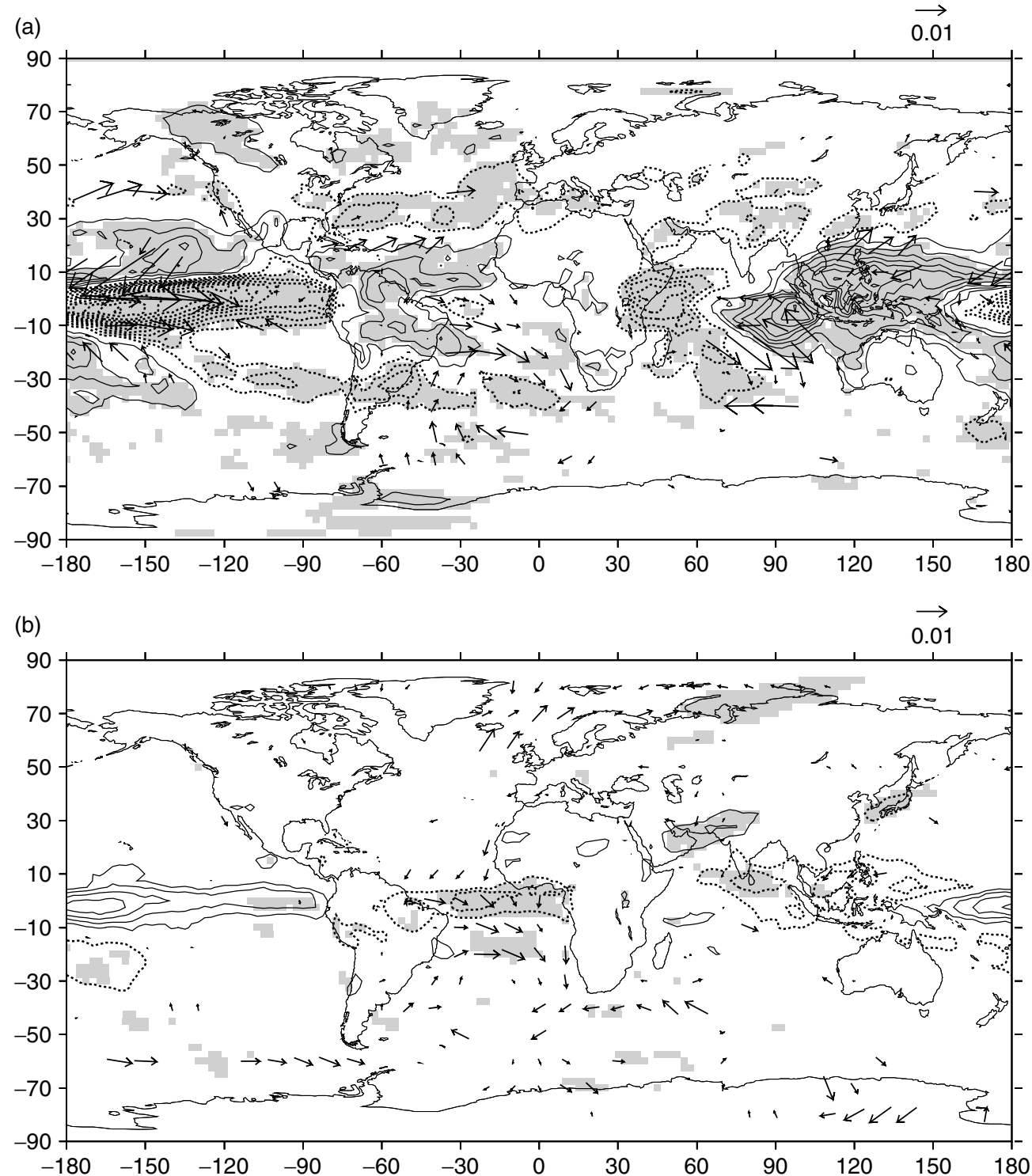

Figure 3. Same as Figure 2 but for OLR anomalies. Contour interval is $2.5 \mathrm{~W} / \mathrm{m}^{2}$, and significant anomalies are shaded. Positive and negative anomalies are contoured by solid, and dotted lines, respectively. The zero contour is omitted

stay in its climatological position. Thus, only the direct ENSO effect weakens the ITCZ (Chiang et al., 2002; Giannini et al., 2004).

By contrast, the enhanced convection over the equatorial strip is a distinctive feature of the ENSOindependent events (Figure 3(b)). This indicates a southward enhancement of the ITCZ, consistent with Handoh and Bigg (2000). The suppressed convection over the tropical Pacific is not statistically significant.

The similar spatial distribution of SST anomalies between the ENSO-associated and ENSO-independent events, but with different OLR and wind anomalies, suggest some differences in atmosphere-ocean interaction in the tropical Atlantic between the different types of events. Noting that both events show two distinct equatorial and off-equatorial zonal bands of SST anomalies, we will explore the dynamics that distinguishes ENSO-associated from ENSO-independent events in Sections 3.3 and 3.4. 


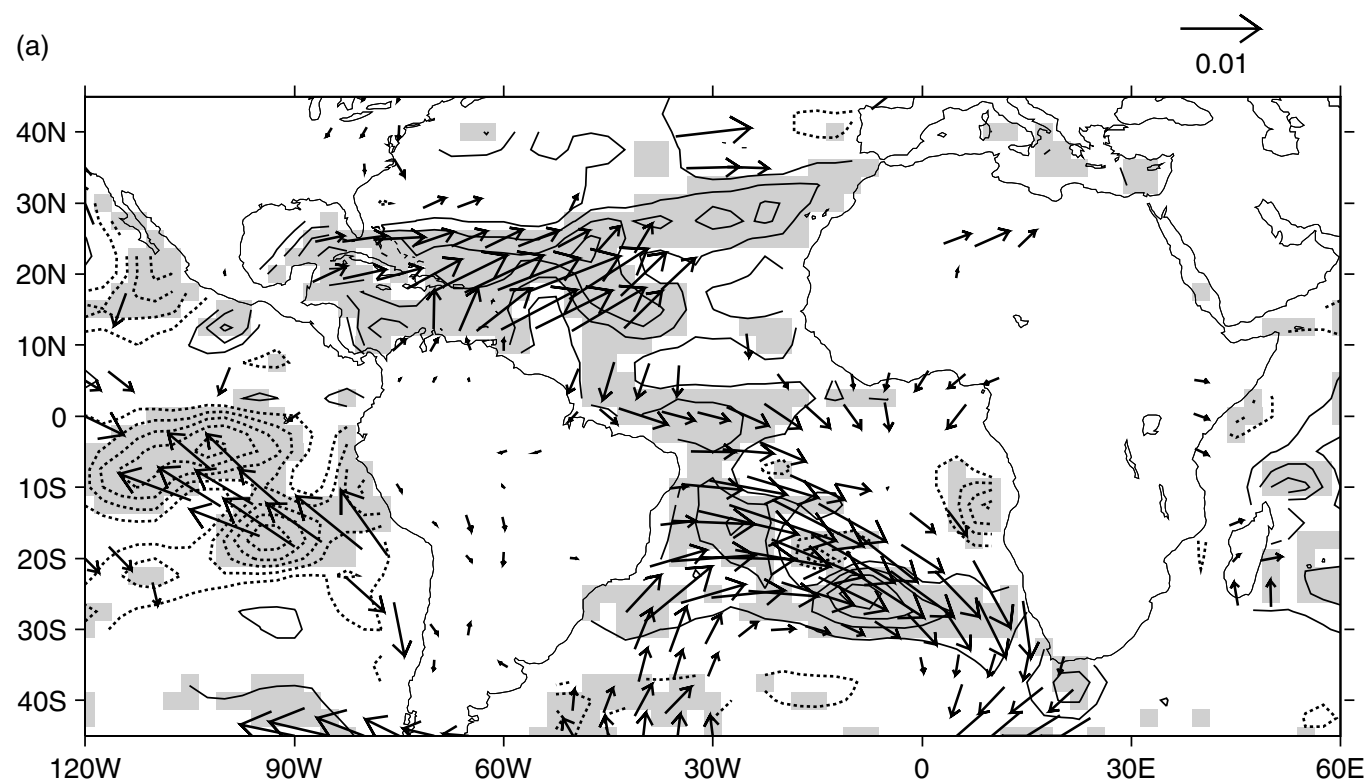

(b)

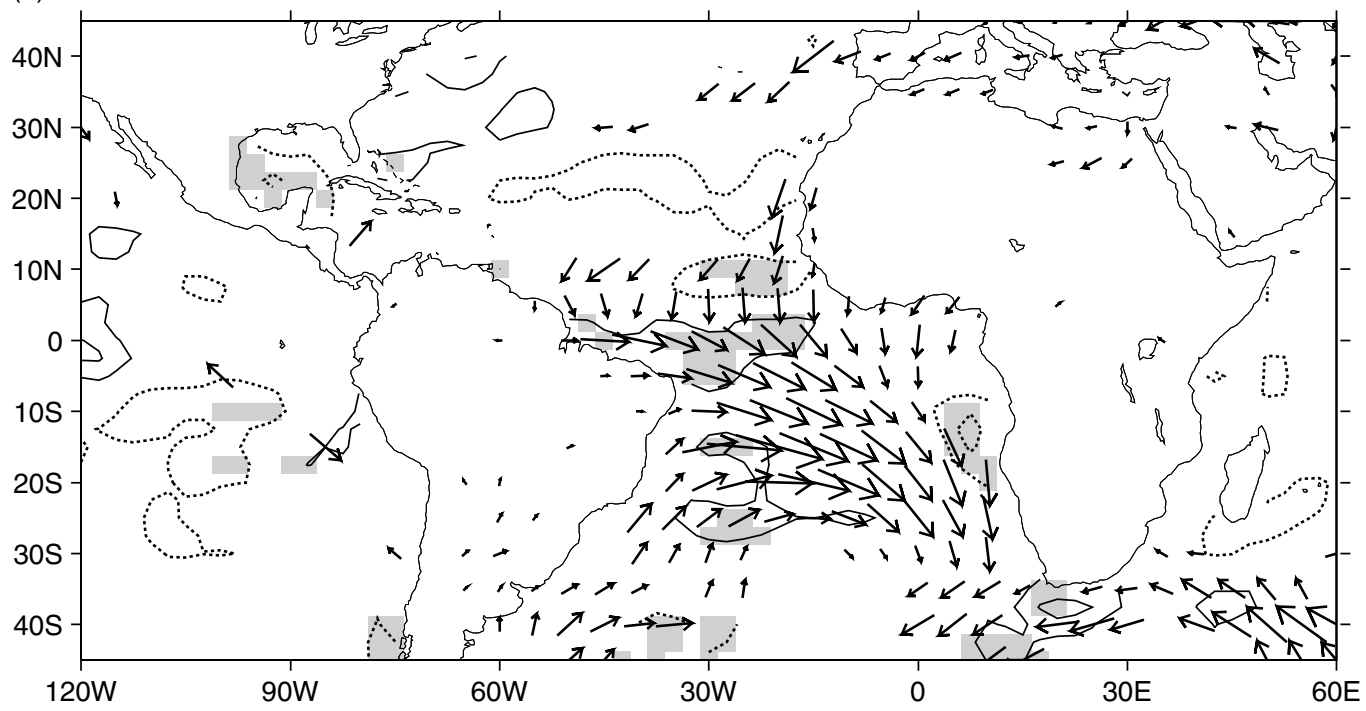

Figure 4. Atlantic composite anomaly maps (SVD 2) of latent heat flux and surface wind stress vectors for (a) ENSO-associated events, (b) ENSO-independent events. Contour interval is $4 \mathrm{~W} / \mathrm{m}^{2}$ and significant anomalies are shaded. Positive and negative anomalies are contoured by solid, and dotted lines, respectively. The zero contour is omitted. Reference wind stress vector is $0.01 \mathrm{~N} / \mathrm{m}^{2}$, and vectors are only plotted (every $5^{\circ}$ ) where either the $x$ or $y$-component is significant

\subsection{Surface flux anomalies}

Next we examine the surface heat fluxes associated with the events discussed in Section 3.1. There are positive latent heat flux anomalies, or an oceanic heat gain (all surface fluxes are defined here as positive downwards), of 4-16 W/m² covering the western equatorial, northern and southern tropical Atlantic during ENSO-associated events (Figure 4(a)) where SST anomalies are positive (Figure 2(a)). The latent heat flux anomalies are associated with a reduction in the strength of southeasterly and northeasterly trade winds, and are indicative of a passive oceanic response to the overlying wind anomalies (Sterl and Hazeleger, 2003; Barreiro et al., 2004; Wu et al., 2004). Consistent with Handoh et al. (2006), our observational analysis does 

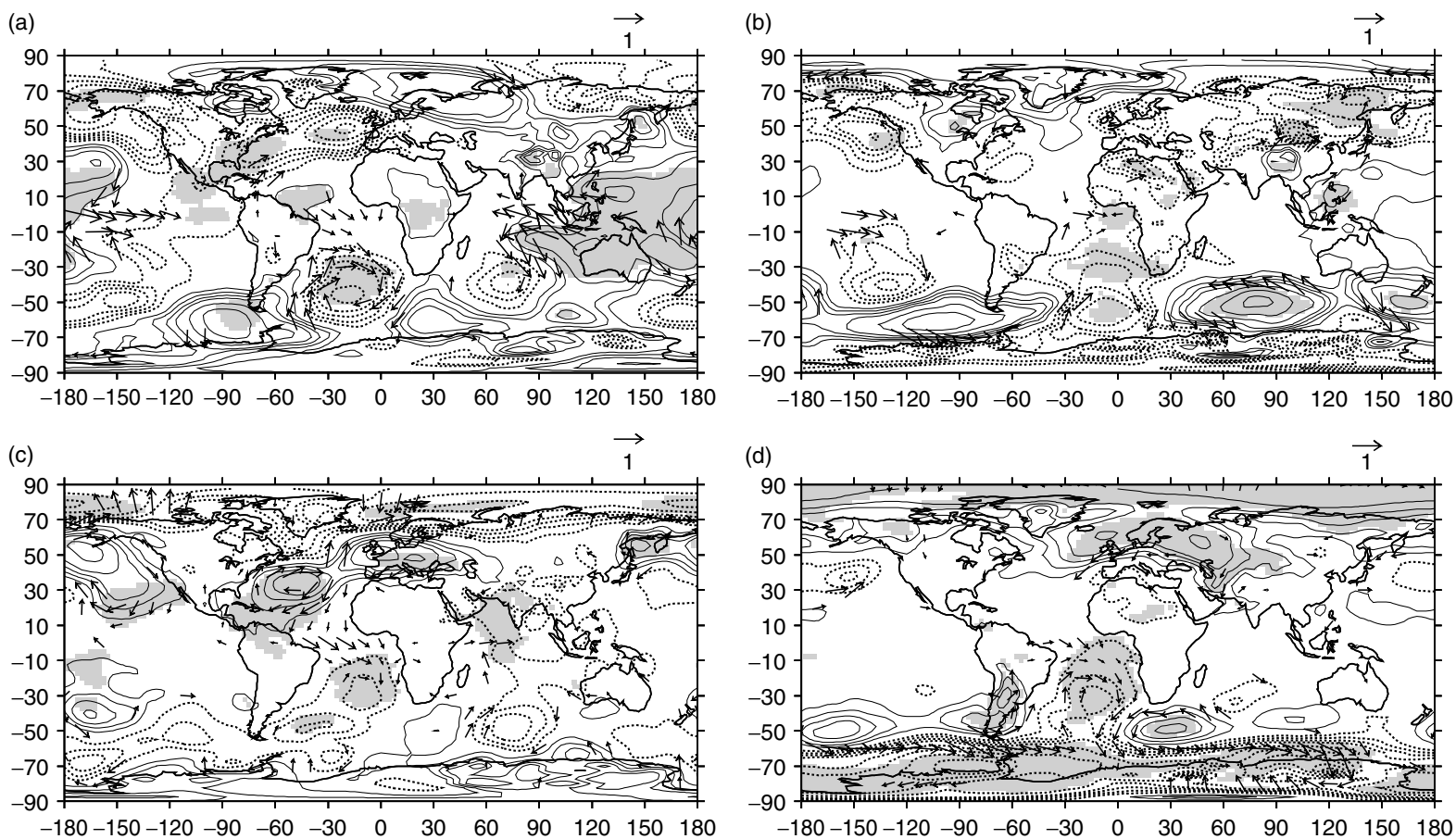

Figure 5. Global composite anomaly maps (SVD 2) for SLP and 1000 hpa vector wind anomalies. Contour interval is 0.25 hpa between $-1 \mathrm{hpa}$ and $1 \mathrm{hpa}$, and otherwise $0.5 \mathrm{hpa}$. Significant anomalies are shaded. ENSO-associated events for (a) DJF, (b) JJA. ENSO-independent events for (c) DJF, (d) JJA. Positive and negative anomalies are contoured by solid, and dotted lines, respectively. The zero contour is omitted. Reference wind vector is $1 \mathrm{~m} / \mathrm{s}^{1}$, and vectors are plotted (every $10^{\circ}$ ) only where either the $x$ or $y$-component is significant

not support a positive WES feedback (Xie and Philander, 1994), although a weak positive feedback over the deep tropics (Joyce et al., 2004) may be at work.

The magnitudes of shortwave radiation anomalies are comparable with those of longwave radiation (neither shown), which are significantly smaller than those of latent heat flux. As we discussed for the North Tropical Atlantic mode (Handoh et al., 2006), the pattern of shortwave anomalies is very similar to that for OLR (Figure 3(a)), because enhanced (suppressed) convection and cloudiness reduces (increases) surface solar insolation. Shortwave radiation anomalies will tend to damp the SST anomalies, but their forcing is partially cancelled out by opposing longwave radiation anomalies. The total surface heat flux anomalies are thus dominated by the latent heat term.

For the ENSO-independent STA events, organised latent heat flux anomalies are restricted to the western equatorial Atlantic basin (Figure 4(b)). This is not consistent with the basin-wide SST anomalies. There are no significant shortwave or longwave radiation anomalies (not shown). Although there are some anomalous cross-equatorial winds towards the south, which lie at the heart of the WES feedback, the heat flux anomalies occur only in the western equatorial Atlantic, west of the SST anomalies. Judging from the spatial coherence of the co-variability of SST, surface wind vector, and OLR anomalies, the overall feedback mechanism over the equatorial region therefore seems to be of the Bjerknes type (Bjerknes, 1969; Xie et al., 1999), consistent with Sutton et al. (2000). Section 3.4 will complement this argument.

Thus, during both ENSO-associated and ENSO-independent STA events the surface heat flux anomalies do not maintain positive SST anomalies over the eastern equatorial Atlantic. Our estimate of the total surface heat fluxes does not support the negative feedback to dampen SST anomalies that has been proposed by Sutton et al. (2000) and Mo and Häkkinen (2001), who employed general circulation model (GCM) outputs and the NCEP-NCAR re-analysis, respectively, for the heat flux estimate. We will examine the temporal evolution of the anomalies to characterise the atmosphere-ocean interaction in Section 3.4. 


\subsection{Global circulation anomalies}

In this section, we describe the global pattern of the STA mode during southern summer (DJF) and winter (JJA) for the (SLP), and stream function and wind vectors at the 1000 hpa and 200 hpa levels.

For the ENSO-associated events in the southern summer season, a cyclonic anomaly is found in the South Atlantic (Figure 5(a)), consistent with Mo and Häkkinen (2001). This exhibits a barotropic structure up into the upper troposphere (Figure 6(a)) and is part of a wave train emanating from the eastern tropical Pacific, where equatorial Rossby wave responses (Figure 6(a)) to the positive SST anomalies and enhanced convection (Figures 2(a) and 3(a)) are identified. ENSO-related circulation anomalies are also found in the tropical East Indian Ocean (Figure 5(a)). A negative SLP anomaly in the sub-tropical to mid-latitude North Atlantic (Figure 5(a)) is similar to the ENSO-associated case of the NTA mode (Handoh et al., 2006), and shows common features of the global atmospheric response to ENSO (Spencer and Slingo, 2004). However, the North Atlantic SLP anomalies shown here are weak and the associated wind anomalies are not significant.

The ENSO-associated STA events show a preference for the southern summer season, and during the southern winter in the ENSO-associated case, the anomalies over the North Atlantic sector are weakened (Figures 5(b) and 6(b)), although wave trains from the central and eastern tropical Pacific can be identified. In the Southern Hemisphere, the anomalies are also weaker during southern winter (Figures 5(b) and 6(b)). A low wave number wave train emanates from the central-eastern tropical Pacific and appears to be guided over the mid-latitudes by the Southern Hemisphere jet (Hoskins and Ambrizzi, 1993), which is enhanced during this season. A high wave number component appears to be refracted towards southern Africa.

In contrast to the ENSO-associated events, there are strong anomalies over the tropical Atlantic during the ENSO-independent events. The 200-hPa equatorial easterly anomalies together with the off-equatorial anticyclonic anomalies can be interpreted as an equatorial Rossby wave response to the enhanced convection (the negative OLR anomalies in Figure 3(b)) during the southern summer (Figure 6(c)). The equatorial easterly anomalies over the Indian Ocean can be at least partially attributed to the enhanced convection in that region.
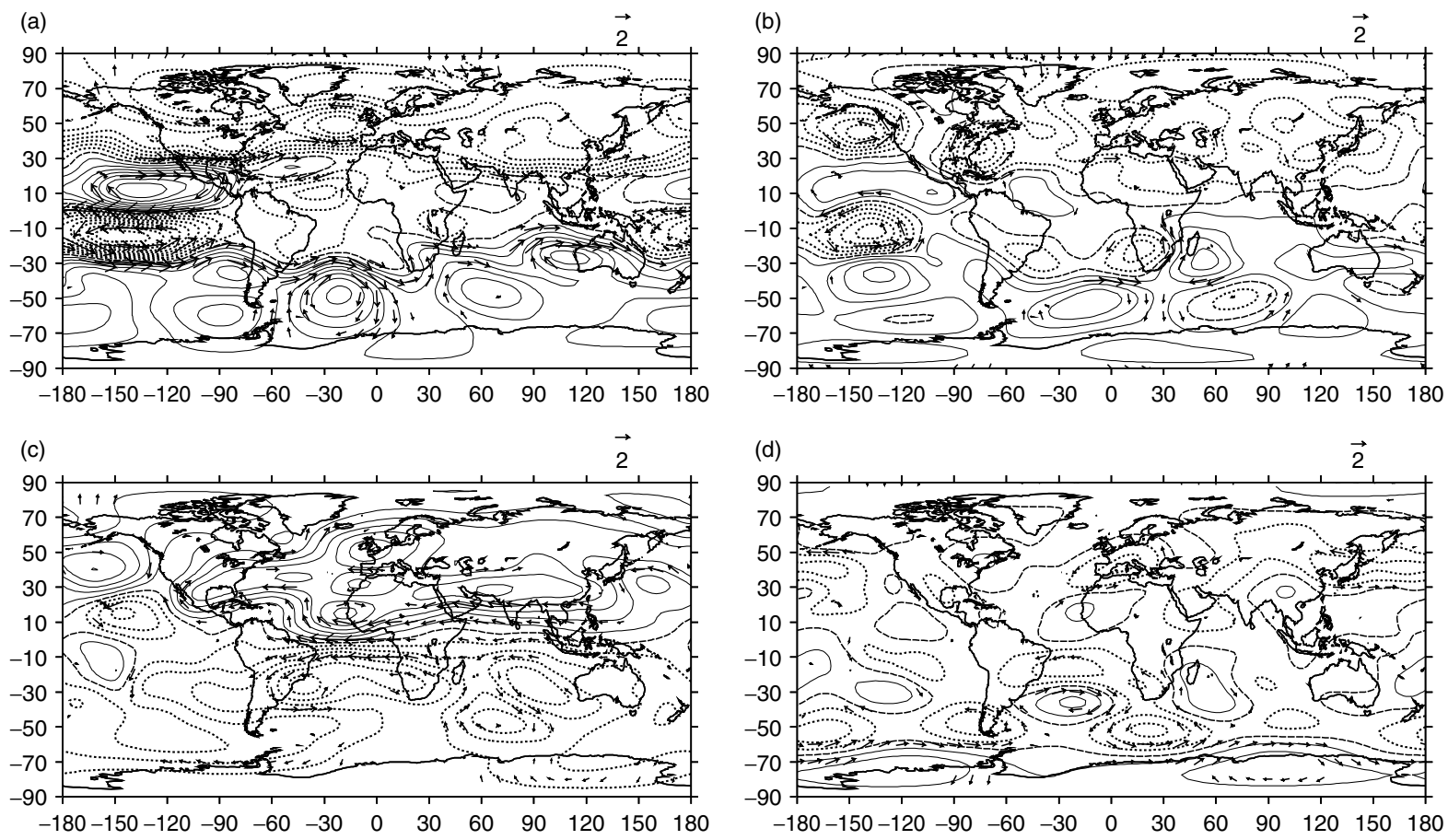

Figure 6. Same as Figure 5 but for the 200 hpa level streamfunction, and vector wind anomalies. Streamfunction contour interval is $8 \times 10^{5} \mathrm{~m}^{2} / \mathrm{s}^{1}$. Positive and negative anomalies are contoured by solid and dotted lines, respectively. The zero contour is dashed.

Reference wind vector is $2 \mathrm{~m} / \mathrm{s}^{1}$, and vectors are plotted (every $10^{\circ}$ ) only where either the $x$ or $y$-component is significant 
Significant SLP and circulation anomalies are found in the Northern Hemisphere (Figures 5(c) and 6(c)). Cross-equatorial flow over the tropical Atlantic occurs only during the southern summer (Figure 5(c), (d)), but it is strong enough to appear in the composite annual map (Figure 2(b)). This is associated with the southern part of the anti-cyclonic anomaly extending from the sub-tropical Atlantic to Europe. This is a notable difference from the ENSO-associated events, which show a cyclonic anomaly of similar magnitude. The sub-tropical cyclonic anomaly in the South Atlantic during the northern winter (Figure 5(c)) is weaker than in the ENSO-associated events (Figure 5(a)). Recall that the preferred season for ENSO-independent events is April-July (see also Cabos Narvaez et al., 2002).

A strong negative SLP anomaly is found over the high-latitudes in the Southern Hemisphere during the southern winter, part of which has a barotropic structure up to $200 \mathrm{hpa}$ (Figures 5(d) and 6(d)). A wave train emanating from the western tropical Pacific is similar to the Pacific-South-America (PSA) pattern (Mo and Paegle, 2001; Huang, 2004). Another wave train departing from the tropical Atlantic has two major components: the high and low wave-number components reach the southwestern Indian Ocean, and the eastern Pacific, via the Indian Ocean section of Antarctica, respectively. The latter wave train may influence the tropical Pacific.

\subsection{Dynamic evolution of the anomalies}

Here we examine the evolution of anomaly patterns. Lag composite maps of the SST and surface vector wind anomalies are shown in Figure 7, and zonal propagation of the equatorial and off-equatorial anomalies are shown in Figure 8. We will discuss how these surface anomalies are related to the lower and upper tropospheric dynamical fields presented in Figures 9 and 10. Note that the SST patterns in the STA between ENSO-associated and ENSO-independent events do not differ (Figure 7(c) and (h)) significantly in month 0. Perhaps, this is why our method resulted in reducing the equatorial and sub-tropical modes into a single STA mode (Figure 1; see also Mayer and Enfield (1997) and Mo and Häkkinen (2001)).

3.4.1. ENSO-associated STA event. Lagged composite maps show the temporal evolution of the SST and surface wind anomalies for the ENSO-associated STA events (Figure 7(a-e)). Positive SST anomalies over the $30-45^{\circ} \mathrm{S}$ band are identified in the South Atlantic 6 months before the event peak (Figure 7(a), (f)). These are consistent with reduced evaporation caused by a weakening of the westerlies, which occurs at the northern edge of a barotropic anticyclonic gyre extending through the troposphere (Figure 9(a), (f)) in month -9. This anomaly in the South Atlantic is part of a Southern Hemisphere wave train emanating from the western Pacific.

In the sub-tropical Atlantic, at month -6 , there are statistically significant northwesterly surface wind anomalies, but as yet, not significant SST anomalies. By month -3 , the circulation pattern over the South Atlantic has reversed, such that there are sub-tropical surface northwesterly anomalies that reduce the total wind speed, decrease the latent heat flux, and lead to the warm SST anomalies over the sub-tropical South Atlantic (Figure 5(b)). These surface wind anomalies are associated with a cyclonic anomaly that in turn is part of a PSA-like wave train from the South Pacific (Figure 9(c), (h)), similar to that in Mo and Häkkinen (2001). During month -3 , when El Niño peaks, positive SST anomalies peak in the equatorial and off-equatorial eastern tropical Atlantic (Figure 7(b)). However, the overall STA pattern appears in month 0, when the El Niño has passed its peak. Thus, the time-evolution of ENSO-STA relationships (with a roughly one season lag) is in good agreement with that previously reported (Mo and Häkkinen, 2001). The physical link between the ENSO and STA anomalies appears to be partially through an extra-tropical PSA-like wave train (Huang, 2004).

The zonal propagation of the SST and westerly wind stress anomalies during ENSO-associated STA events is shown in Figure 8. Westward propagation of the SST anomalies at both $5^{\circ} \mathrm{S}$ and $15^{\circ} \mathrm{S}$ is observed, with a speed of about $0.27 \mathrm{~m} / \mathrm{s}^{1}$. The SST anomalies lag the westerly wind stress anomalies by about 3 months, consistent with the atmosphere forcing the ocean through latent heat flux anomalies.

Although there are positive SST over the tropical Atlantic, this does not lead to enhanced convection there, as shown by the lack of negative OLR anomalies in Figure 3(a). This appears to be due to an anomalous Walker Circulation between the equatorial Pacific and Atlantic (see Ruiz-Barradas et al., 2003) that develops 

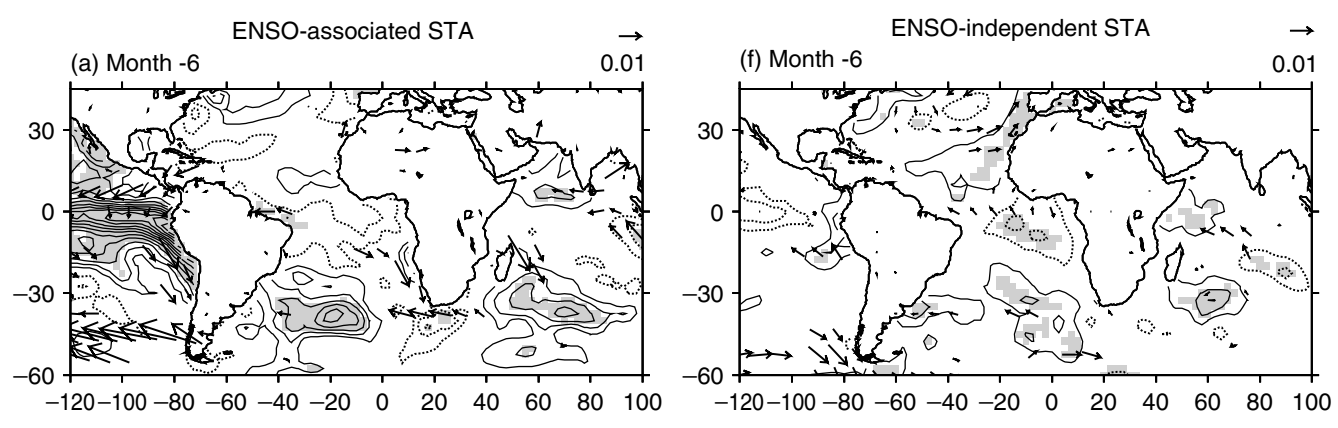

(b) Month -3

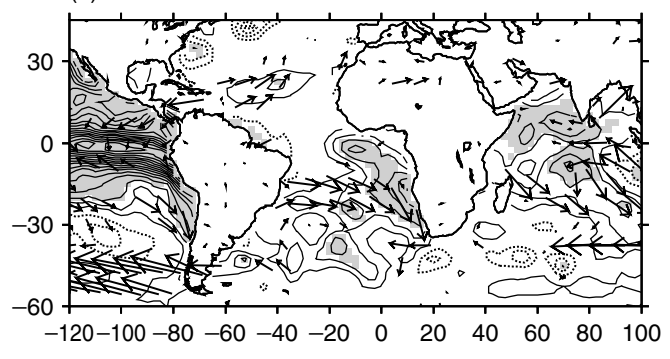

(g) Month -3

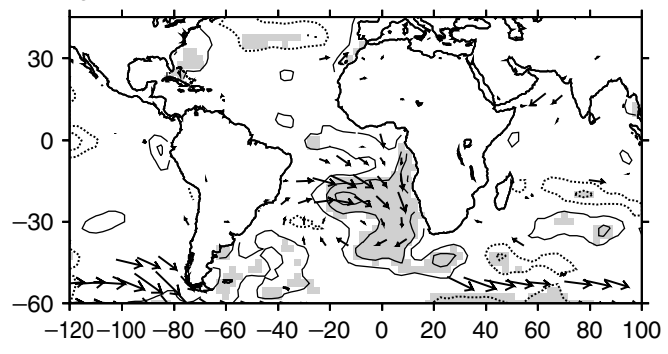

(c) Month 0

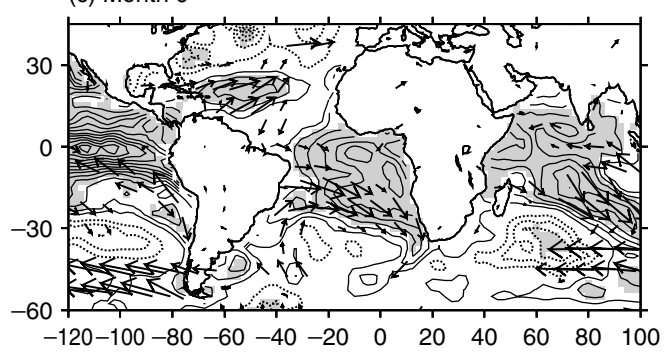

(h) Month 0
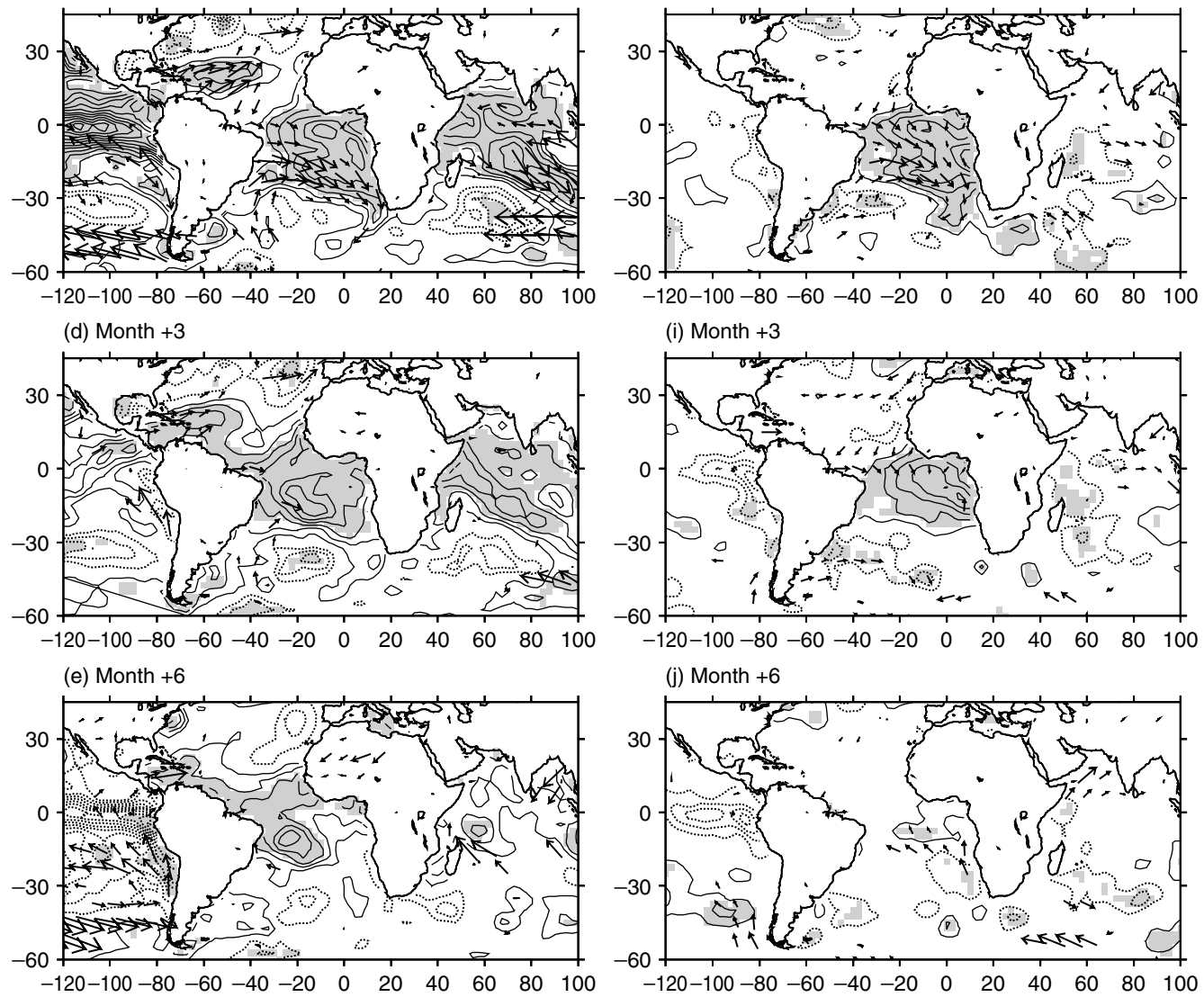

Figure 7. Lag composite maps for SST and surface wind vectors anomalies. (a) -6 , (b) -3 , (c) 0 , (d) +3 , and (e) +6 months for ENSO-associated events. (f) -6 , (g) -3 , (h) 0, (i) +3 , and (j) +6 months for ENSO-independent events. SST anomalies contour interval is $0.1{ }^{\circ} \mathrm{C}$, and significant anomalies are shaded. Positive and negative anomalies are contoured by solid and dotted lines, respectively. The zero contour is omitted. The reference surface wind stress vector is $0.01 \mathrm{~N} / \mathrm{m}^{2}$, and vectors are plotted (every $7.5^{\circ}$ ) only where either the $x$ or $y$-component is significant 

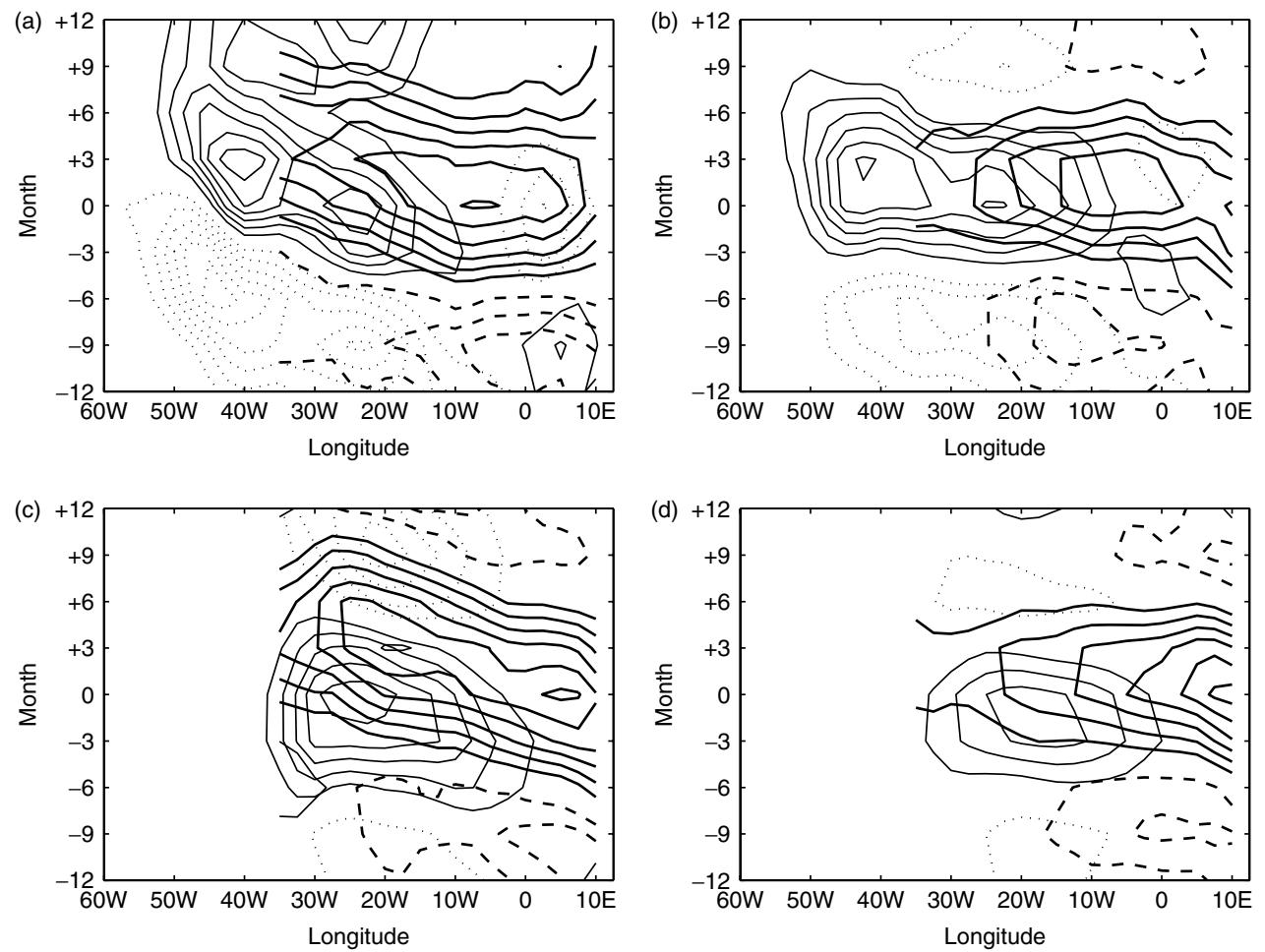

Figure 8. Hovmöller diagrams of the SST and $\tau_{x}$ anomalies, based on the lag composite maps in Figure 7. (a) ENSO-associated events and (b) ENSO-independent events for $5^{\circ} \mathrm{S}$. (c) ENSO-associated events and (d) ENSO-independent events for $15^{\circ} \mathrm{S}$. SST anomalies contour interval is $0.1{ }^{\circ} \mathrm{C}$. Positive and negative anomalies are contoured by thick solid and dashed lines, respectively. Thin solid and dotted lines are used for $\tau_{x}$ anomalies, with contour interval of $2 \times 10^{-3} \mathrm{~N} / \mathrm{m}^{2}$, and $3 \times 10^{-3} \mathrm{~N} / \mathrm{m}^{2}$ for ((a) and (b)) and ((c) and (d)), respectively. The zero contour is omitted

by month -6 . The equatorial lower-tropospheric easterly anomalies (Figure 9(b)) and upper-tropospheric westerly anomalies (Figure $9(\mathrm{~g})$ ) can be interpreted as an equatorial Kelvin wave response to the enhanced ENSO-related convection over the Pacific. The descending branch of this equatorial Kelvin wave structure over the tropical Atlantic would act to suppress convection there and counter the effect of the positive SST anomalies.

In month 0, a strong barotropic cyclonic anomaly extended from the northern sub-tropical Atlantic to Europe (Figure 9(d) and (i)). This forms part of a wave train emanating from the eastern Pacific and is a characteristic of ENSO-associated events during the boreal winter, as discussed in Section 3.3 (see Figures 5(a) and 6(a)). The southwesterly wind anomalies over the sub-tropical North Atlantic are responsible for the maintenance of corresponding positive SST anomalies (Figure 7(c) and (d)). ENSO signals disappear in month +3 , and the tropical Atlantic SST anomalies largely disappear by month +6 (Figure 7(e)), while the atmospheric anomalies are retained (Figure 9(e) and (j)). By this time, the La Niña phase of the ENSO cycle appears with positive SST anomalies over the equatorial Atlantic during the southern Autumn season (Saravanan and Chang, 2000).

In summary, the ENSO-associated events appear to be forced by a PSA wave train emanating from the central Pacific as well as a change in the Walker Circulation. The SST anomalies of the South Atlantic lag ENSO by 1 month (see Section 2). On the basis of the SST-OLR relationship, the ENSO-associated STA events cannot be considered as active examples of coupled atmosphere-ocean interaction.

3.4.2. ENSO-independent STA event. The ENSO-independent STA events develop slightly differently to the ENSO-associated events. At month -6 , the remnants of the previous negative phase of the STA event remain, with negative SST anomalies in the eastern tropical Atlantic (Figure 7(f)). Meanwhile, a mid-latitude wave 
$850 \mathrm{hPa}$

(a) Month -9

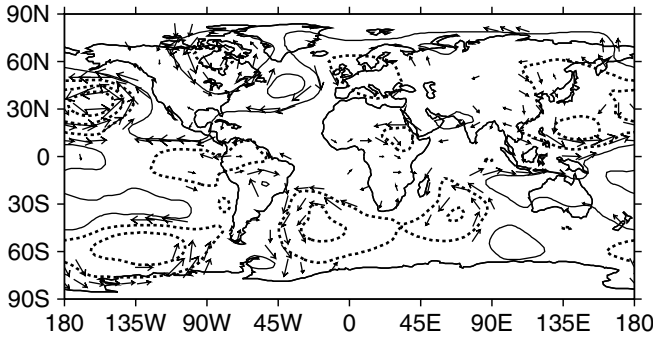

(b) Month -6

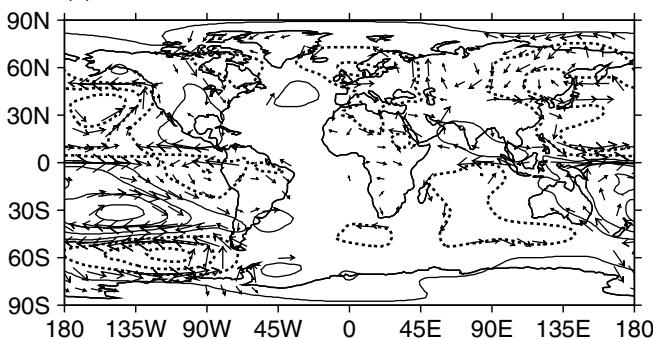

(c) Month -3

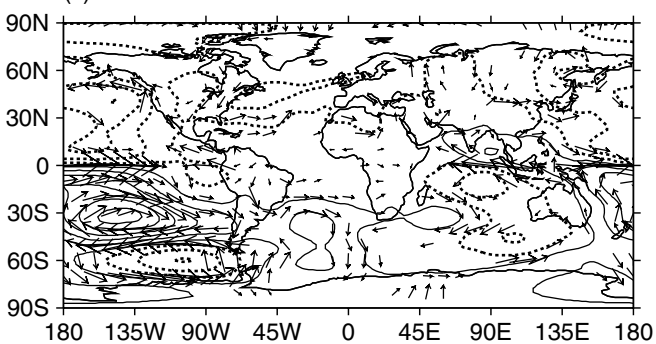

(d) Month 0

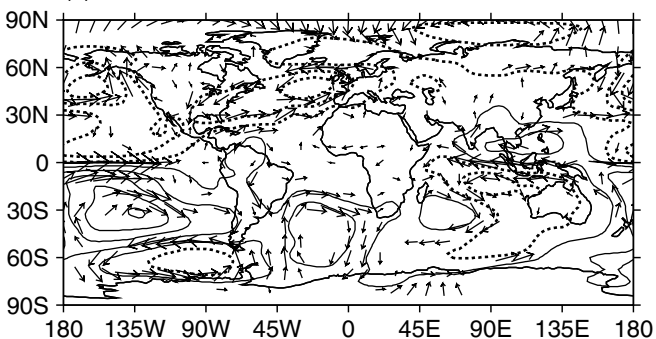

(e) Month +6

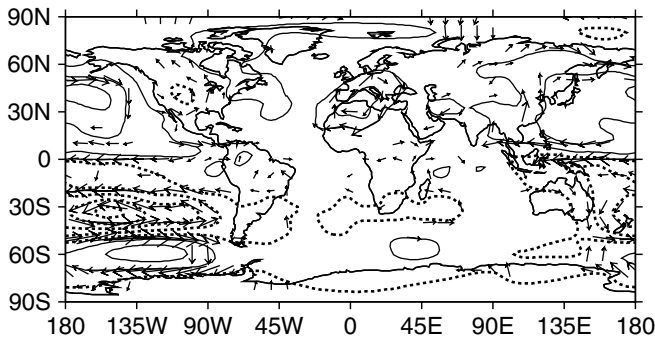

$200 \mathrm{hPa}$

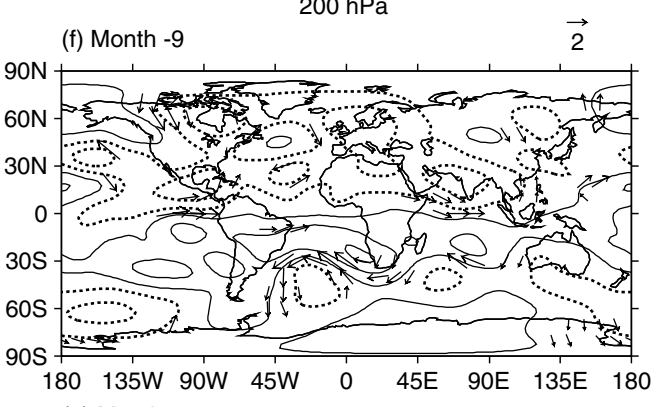

(g) Month -6

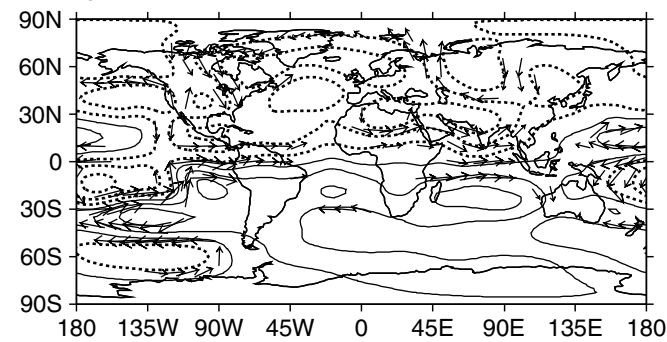

(h) Month -3
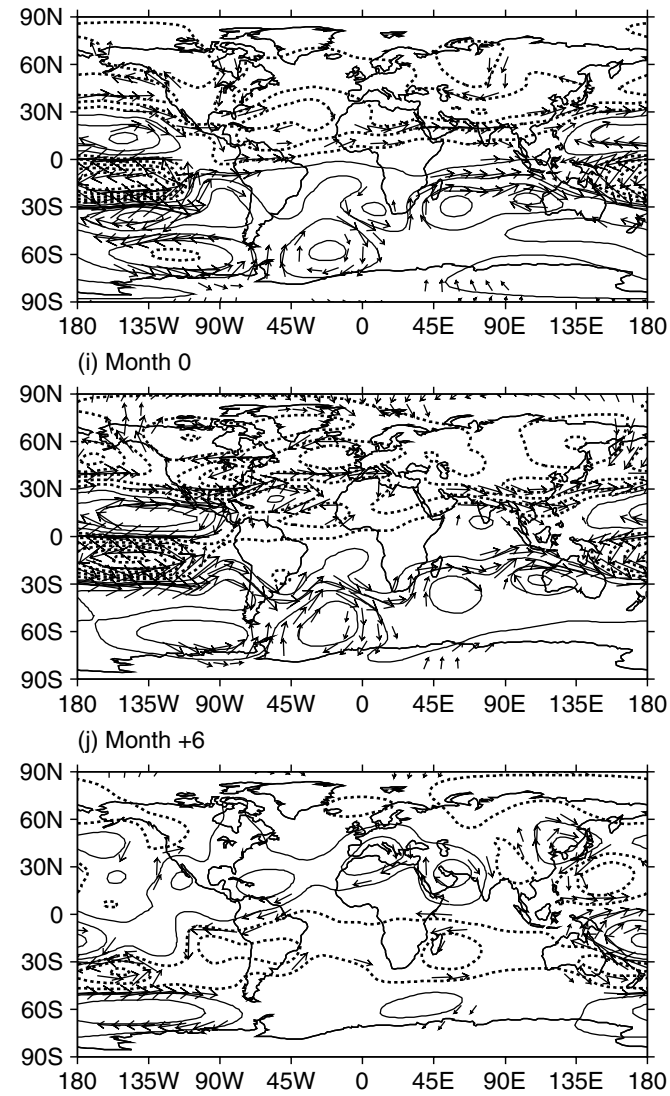

Figure 9. Lag composite maps for 850 and 200 hpa streamfunction, and vector wind anomalies for ENSO-associated events. (a), (f) -9, (b), (g) -6 , (c), (h) 3, (d), (i) 0, and (e), (j) +6 months for 850 and $200 \mathrm{hPa}$ level, respectively. Stream function contour intervals are 6 and $12 \times 10^{5} \mathrm{~m}^{2} / \mathrm{s}^{1}$ for 850 and $200 \mathrm{hPa}$ levels, respectively. Positive and negative anomalies are contoured by solid and dotted lines, respectively. The zero contour is omitted. Reference wind vectors are shown on the top of (a) and (f). Vectors are plotted (every $7.5^{\circ}$ ) only where either the $x$ or $y$-component is significant 
(a) Month -9

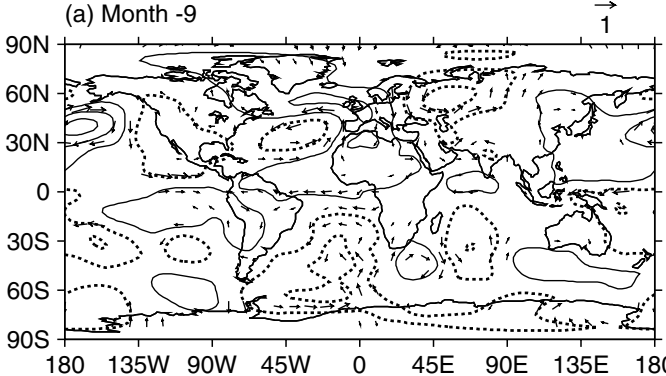

(b) Month -6

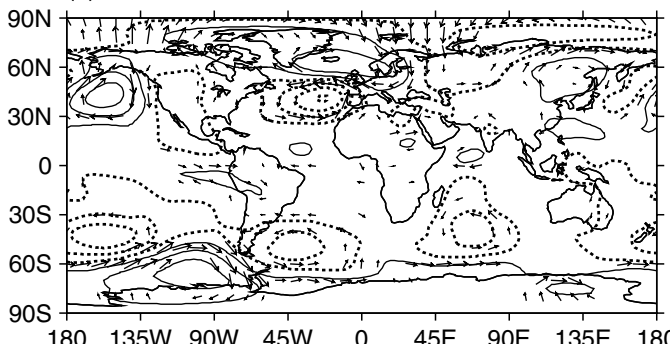

(c) Month -3

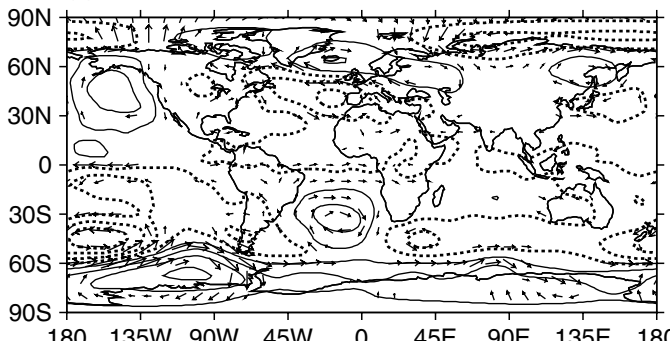

(d) Month 0

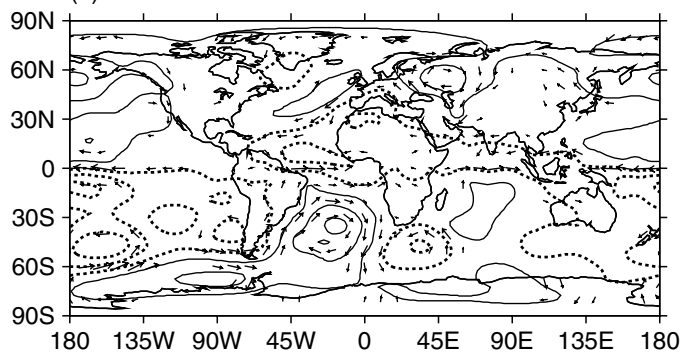

(e) Month +6

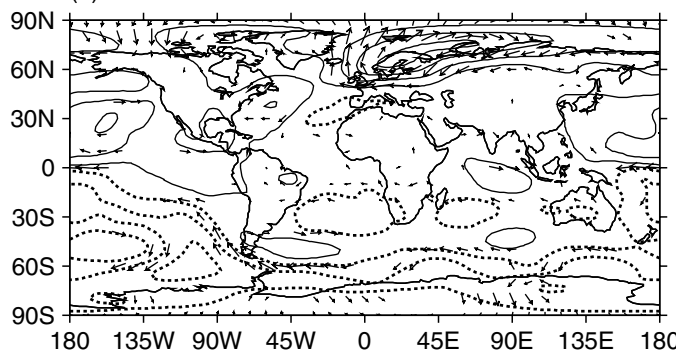

$200 \mathrm{hPa}$

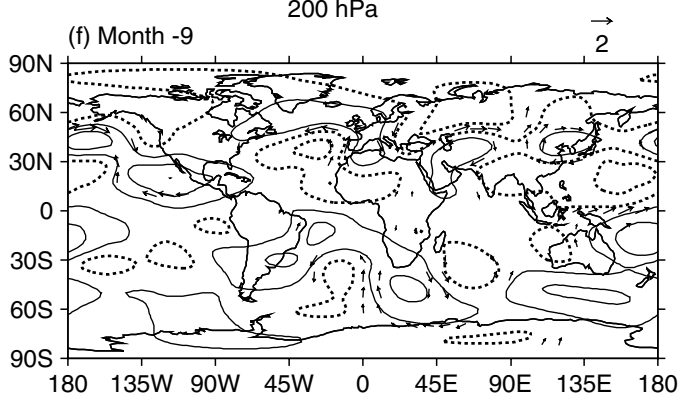

(g) Month -6

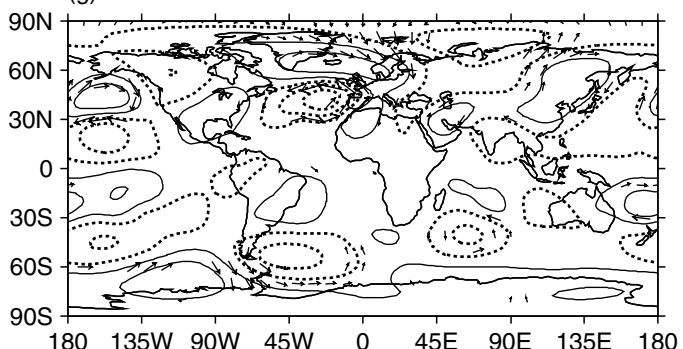

(h) Month -3

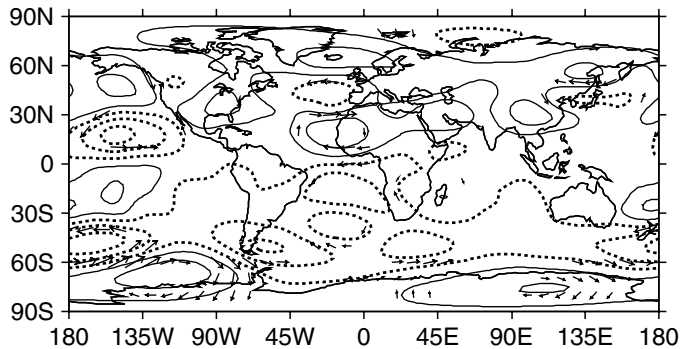

(i) Month 0

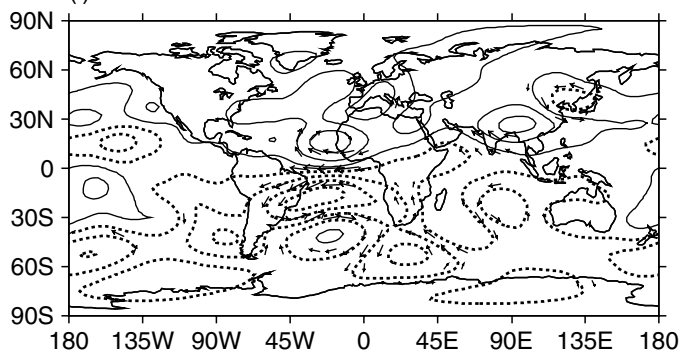

(j) Month +6

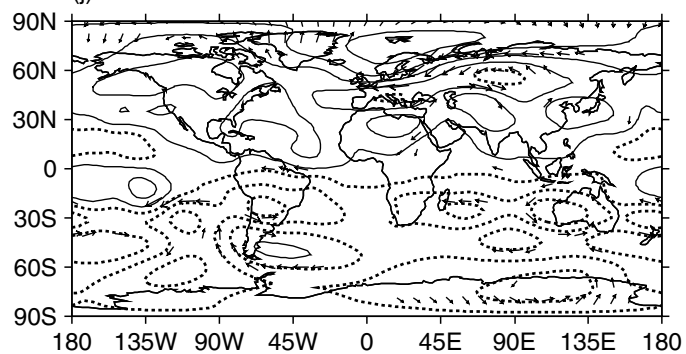

Figure 10. Same as Figure 9, but for ENSO-independent events. Stream function contour intervals are 4 and $8 \times 10^{5} \mathrm{~m}^{2} / \mathrm{s}^{1}$ for 850 and $200 \mathrm{hPa}$ levels, respectively 
train emanates from the western tropical Pacific and propagates over the Southern Ocean before recurving northwards over the South Atlantic (Figure 10(b), (g)). This wave train seems to have a higher wave number than that found by Mo and Häkkinen (2001). The equatorward extension of this wave train has surface northwesterly anomalies which then develop together with positive SST anomalies over the eastern South Atlantic at month -3 (Figure 7(g)).

By month +6 , the positive SST anomalies have largely disappeared and the event is over (Figure $7(\mathrm{j})$ ). This can be compared with the longer lasting ENSO-associated STA events, where there is still a significant positive SST anomaly at month +6 (Figure 7(e)).

The SST anomalies in the ENSO-independent event do not appear to just arise as a passive response to the atmospheric forcing. They lead to enhanced convection (negative OLR anomalies) along the equator (Figure 3(b)), representing a southward shift of the ITCZ. Part of the atmospheric anomalies at and following the peak of the STA event can be interpreted as a response to this enhanced convection. At month 0 , lower-tropospheric equatorial westerly anomalies and a cyclonic anomaly in the sub-tropical North Atlantic (Figure 10(d)), and upper-tropospheric equatorial easterly anomalies together with a pair of sub-tropical anticyclonic anomalies (Figure 10(i)) can be interpreted as an equatorial Rossby wave response to the enhanced convection. These appear to force an extra-tropical wave train in the Southern Hemisphere (Ruiz-Barradas et al., 2000), which propagates over the Southern Ocean into the Indian Ocean sector (Figure 10(i)). In the Northern Hemisphere, a wave train leads to a cyclonic anomaly over Europe at month 0 (Figure 10(d)). This cyclonic anomaly persists well after the tropical Atlantic SST anomalies have decayed in month 6 (Figure 10(e)), and extends further eastward over Asia. Within the North Atlantic these atmospheric anomalies are consistent with those in the quasi-biennial equatorial mode of Tourre et al. (1999).

The westward propagation speed of the Atlantic SST and surface wind stress anomalies is much faster in ENSO-independent events (Figure 8(c), (d)) compared to the ENSO-associated events. In month -6, negative SST anomalies are found along the equatorial Atlantic. This occurs at the end of the negative phase of such an ENSO-independent event (Figure 7(f)). The first indication of the positive phase of the STA event in the tropics is the weakening of the surface trades over the Gulf of Guinea in month -6 (westerly anomalies at $0{ }^{\circ} \mathrm{E}$ in Figure 8(b)). This would excite an eastward propagating, oceanic downwelling Kelvin wave. Thus the initiation of such Kelvin wave propagation does not necessarily come from the western equatorial Atlantic, unlike those previously reported (Servain et al., 1982; Huang and Shukla, 1997; Handoh and Bigg, 2000). The arrival of the Kelvin wave at the African coast would then excite a number of westward-propagating Rossby waves, consistent with the positive SST anomalies that propagate westwards from the coast, both near (Figure 8(b)) and off the equator (Figure 8(d)). These SST anomalies would then induce an atmospheric circulation with westerly and easterly anomalies to the west and east, respectively, of the maximum SST anomalies, consistent with the observations in Figure 8(b), (d). Near the equator, the arrival of positive SST anomalies off the coast of Brazil is accompanied by surface westerly anomalies. The westward propagating SST anomalies induce surface easterly anomalies, east of the SST maximum, which in turn would excite an eastward-propagating oceanic upwelling Kelvin wave, the trigger of the negative phase of the event. Thus, the ENSO-independent STA events can display self-sustaining warm-cold cycles. The westward propagation of SST, wind, and OLR anomalies is consistent with Hirst's (1988) theoretical model II, although this unstable mode would favour the size of the tropical Pacific basin rather than that of the tropical Atlantic.

\section{CONCLUSIONS}

Following the methodology presented in Handoh et al. (2006), we have analysed the global patterns associated with inter-annual coupled ocean-atmosphere variability of the STA. There is a clear difference between the two cases with and without ENSO influence, as expected from our analysis of the NTA mode (Handoh et al., 2006). For the ENSO-associated case, peak SST and zonal wind stress anomalies in the STA lag ENSO by 1 month. However, this correlation appears to be dominated by the equatorial anomalies. The overall SST anomalies lag ENSO by one season, consistent with previous reports (Enfield and Mayer, 1997; Latif and Grötzner, 2000; Mo and Häkkinen, 2001). Our analysis suggests that the ENSO-associated events are forced by a wave train emanating from the central Pacific in addition to a change in the Walker circulation due to 
the atmospheric equatorial Kelvin wave response to ENSO. By contrast, the ENSO-independent case showed that the tropical Atlantic anomalies could be forced by a Southern Hemisphere wave train that originated over the western Pacific (e.g. Mo and Paegle, 2001). This suggests that tropical Atlantic warm/cold events can be caused by non-ENSO stochastic forcing, consistent with Handoh et al. (2006).

Interestingly, for both ENSO-associated and -independent events, the equatorial and off-equatorial components of the STA mode seem to behave independently. The two components can then be considered as independent modes as in previous studies (Huang et al., 2004; Wu et al., 2004). However, our method is necessarily of limited value in defining the modes comparable with previous work that includes the Benguela Niño (Florenchie et al., 2004), as we have emphasised the co-variability of the SST and surface wind anomalies, and clear separation between ENSO-associated and -indepedendent events. In fact, the dynamical behaviours are proven to be different for the equatorial and sub-tropical components only when the ENSO-associated events are separated from ENSO-independent events.

Ocean-atmosphere coupling processes are identified whichever season is examined (Section 3.2). The WES feedback (Xie and Philander, 1994) is not a plausible mechanism for locally maintaining the mode over the off-equatorial regions during the ENSO-associated events. Rather, the off-equatorial SST anomalies appear to be a passive oceanic response to the induced change in the overlying trade winds (Sterl and Hazeleger, 2003; Barreiro et al., 2004). The nature of this mechanism is very similar to that of the NTA mode (Handoh et al., 2006). By contrast, the feedback mechanism for ENSO-independent events is attributed to off-equatorial westward-propagating oceanic Rossby-like waves.

The westward propagation of equatorial and off-equatorial SST anomalies is the main characteristic of the STA mode. Interestingly, we have not confirmed slow eastward-propagating SST anomalies from the western to central equatorial Atlantic previously identified (Philander, 1986; Delecluse et al., 1994; Latif and Grötzner, 2000; CabosNarvaez et al., 2002). ENSO-independent events display westward-propagating coupled ocean-atmosphere behaviour similar to Hirst's $(1986,1988)$ model II. Handoh and Bigg (2000) considered that the initiating mechanism of the 1995-1997 EAO was a westerly wind burst in the western tropical Atlantic. However, our analysis suggests that, more typically, westerly wind anomalies over the eastern equatorial Atlantic, are precursors of the EAO, and that STA ENSO-independent events are an internal selfsustaining oscillation of the equatorial Atlantic, supporting the hypotheses proposed by Handoh and Bigg, (2000) and Tseng and Mechoso (2001). Our analysis also supports the idea that such events are independent of ENSO signals.

Together with the companion paper (Handoh et al., 2006), our observational analysis of the inter-annual coupled tropical Atlantic modes allows us to develop a unified view of NTA and STA modes. The events, and their causal and ocean-atmosphere feedback mechanisms, are summarised in Table 1. Broadly speaking, most of their characteristics are consistent with previous work (Enfield and Mayer, 1997; Saravanan and Chang, 2000; Sutton et al., 2000; Ruiz-Barradas et al., 2000; Mo and Häkkinen, 2001; Huang, 2004). What we have shown, however, is the clear separation of processes in the presence and absence of ENSO in the Pacific. These differences between ENSO-associated and ENSO-independent events are not only in spatial extent but also in how the event develops. Stochastic atmospheric wave trains from the Pacific basin appear to be important forcing mechanisms for the excitation of off-equatorial ENSO-independent events in the Atlantic (both NTA and the off-equatorial component of STA). The nature of the ocean-atmosphere interaction also differs between the events. The extent of tropical ocean-atmosphere coupling that generates diabatic heating is very limited during ENSO-associated events, while the heating anomaly generated in ENSO-independent events results in wave trains that propagate towards mid- and high-latitudes.

A major question is whether or not these dynamical links are found in ocean-atmosphere coupled GCMs. As the evolution of ENSO-associated events could be considered as a linear superposition of the STA mode and the remote influence of ENSO, we are currently pursuing this question through a modelling study, to be reported in the future.

\section{ACKNOWLEDGEMENTS}

The NCEP-NCAR re-analysis and OLR data were obtained from the Climate Diagnostics Center (http://www. cdc.noaa.gov). SST data were provided by the British Atmospheric Data Centre. Satellite-derived data 
Table I. Summary of the inter-annual tropical Atlantic modes. The corresponding causal and local ocean-atmosphere interactions are discussed in the main text. Suggested operating feedback mechanisms are passive oceanic response to the overlying wind anomalies (Passive; no feedback), potentially Wind-Evaporation-SST (WES), and Bjerknes feedbacks. The preferred peak seasons are given for both warm (W) and cold (C) events. Note that the STA mode consists of the equatorial (EQ) and off-equatorial (OEQ) components

\begin{tabular}{|c|c|c|c|c|}
\hline Mode & Event type & Causal mechanism & Operating feedback & Peak seasons \\
\hline \multirow[t]{2}{*}{ 1: NTA } & ENSO-associated & PNA-like wave train & Passive & $\begin{array}{l}\text { W: Mar-Jun } \\
\text { C: Feb-May }\end{array}$ \\
\hline & ENSO-independent & $\begin{array}{l}\text { PNA-like wave train } \\
\text { (stochastic origin) }\end{array}$ & $\begin{array}{l}\text { Passive or potentially } \\
\text { WES. A NH wave train } \\
\text { excited at the west } \\
\text { Caribbean }\end{array}$ & $\begin{array}{l}\text { W: Sep-Dec } \\
\text { C:? }\end{array}$ \\
\hline \multirow[t]{2}{*}{ 2: STA } & ENSO-associated & $\begin{array}{l}\text { EQ: Change in Walker } \\
\text { Circulation } \\
\text { OEQ: PSA-like wave } \\
\text { train }\end{array}$ & $\begin{array}{l}\text { EQ: None } \\
\text { OEQ: Passive }\end{array}$ & $\begin{array}{l}\text { W: Nov-Mar } \\
\text { C: Oct-Mar }\end{array}$ \\
\hline & ENSO-independent & $\begin{array}{l}\text { EQ: Self-sustaining } \\
\text { OEQ: PSA-like wave } \\
\text { train (stochastic origin?). }\end{array}$ & $\begin{array}{l}\text { EQ: Bjerknes. NH and } \\
\text { SH wave trains excited } \\
\text { from equator. } \\
\text { OEQ: Passive, but } \\
\text { off-equatorial } \\
\text { westward-propagating } \\
\text { oceanic Rossby-like } \\
\text { wave }\end{array}$ & $\begin{array}{l}\text { W: Apr-Jul } \\
\text { C: Apr-Jun }\end{array}$ \\
\hline
\end{tabular}

to estimate shortwave and longwave radiations were provided by the ISCCP (http://isccp.giss.nasa.gov). We thank the two anonymous reviewers and COAPEC colleagues for constructive criticisms and useful discussions, respectively, that helped to improve the manuscript. ICH has been financially supported by the NERC COAPEC programme (NER/T/S/2000/00295).

\section{REFERENCES}

Barreiro M, Giannini A, Chang P, Saravanan R. 2004. On the role of the South Atlantic atmospheric circulation in tropical Atlantic variability. In Earth Climate: The Ocean-Atmosphere Interaction, Wang C, Xie SP, Carton JA (eds). Geophysical Monograph. AGU: Washington, DC.

Bishop JKB, Rossow WB. 1991. Spatial and temporal variability of global surface solar irradiance. Journal of Geophysical Research 96: $16839-16858$

Bjerknes J. 1969. Atmospheric teleconnection from the equatorial Pacific. Monthly Weather Review 97: 163-172.

CabosNarvaez W, Alvarez García F, Ortizbevía MJ. 2002. Generation of equatorial Atlantic warm and cold events in a coupled general circulation model simulation. Tellus 54A: 426-438.

Carton JA, Huang B. 1994. Warm events in the tropical Atlantic. Journal of Physical Oceanography 24: 888-903.

Chiang JCH, Kushnir Y, Giannini A. 2002. Deconstructing Atlantic ITCZ variability: influence of the local cross-equatorial SST gradient, and remote forcing from the eastern equatorial Pacific. Journal of Geophysical Research 107: 4004, DOI: 10.1029/2000JD000307.

Compo GP, Sadeshmukh PD, Penland C. 2001. Changes of subseasonal variability associated with El Niño. Journal of Climate 14: 2256-3374.

Curtis S, Hastenrath S. 1995. Forcing of anomalous sea surface temperature evolution in the tropical Atlantic during Pacific warm events. Journal of Geophysical Research 100: 15835-15847.

Darnell WL, Gupta SK, Staylor WF. 1983. Downward longwave radiation at the surface from satellite measurements. Journal of Climate and Applied Meteorology 22: 1956-1960.

Delecluse P, Servain J, Levy C, Arpe K, Bengtsson L. 1994. On the teleconnection between the 1984 Atlantic warm event and the 1982-83 ENSO. Tellus 46: 448-464.

Diaz H, Hoerling M, Eischeid J. 2001. ENSO variability, teleconnections and climate change. International Journal of Climatology 21: $1845-1862$.

Dommenget D, Latif M. 2000. Interannual to decadal variability in the tropical Atlantic. Journal of Climate 13: 777-792.

Enfield DB, Mayer DA. 1997. Tropical Atlantic sea surface temperature variability and its relation to El Niño-Southern Oscillation. Journal of Geophysical Research 102: 929-945. 
Fairall CW, Bradley EF, Rogers DP, Edson JB, Young GS. 1996. Bulk parameterization of air-sea fluxes for tropical ocean-global atmosphere coupled-ocean atmosphere response experiment. Journal of Geophysical Research 101: 3474-3764.

Florenchie P, Reason CJC, Lutjeharms JRE, Rouault M, Roy C, Masson S. 2004. Evolution of interannual warm and cold events in the Southeast Atlantic Ocean. Journal of Climate 17: 2318-2334.

Giannini A, Chiang JCH, Cane MA, Kushnir Y, Seager R. 2001. The ENSO teleconnection to the tropical Atlantic Ocean: contributions of the remote and local SSTs to rainfall variability in the tropical Americas. Journal of Climate 14: 4530-4544.

Gupta SK, Darnell WL, Wilber AC. 1992. A parameterization for longwave surface radiation from satellite data: Recent improvements. Journal of Applied Meteorology 31: 1359-1367.

Handoh IC, Bigg GR. 2000. A self-sustaining climate mode in the tropical Atlantic, 1995-1997: Observations and modelling. Quarterly Journal of the Royal Meteorological Society 126: 807-821.

Handoh IC, Matthews AJ, Bigg GR, Stevens DP. 2006. Interannual variability of the tropical Atlantic independent of and associated with ENSO: Part I. The North tropical Atlantic. International Journal of Climatology DOI:10.1002/joc1343.

Hirst AC. 1986. Unstable and damped equatorial modes in simple coupled Ocean-atmosphere models. Journal of the Atmospheric Sciences 43: 606-632.

Hirst AC. 1988. Slow instabilities in tropical Ocean basin-global atmosphere models. Journal of the Atmospheric Sciences 45: $830-852$.

Horel JD, Kousky VE, Kagano MT. 1986. Atmospheric conditions in the Atlantic sector during 1983 and 1984. Nature 322: $240-243$.

Hoskins BJ, Ambrizzi T. 1993. Rossby wave propagation on a realistic longitudinally varying flow. Journal of the Atmospheric Sciences 50: $1661-1671$.

Huang B. 2004. Remotely forced variability in the tropical Atlantic Ocean. Climate Dynamics 23: 133-152.

Huang B, Shukla J. 1997. Characteristics of the interannual and decadal variability in a general circulation model of the tropical Atlantic Ocean. Journal of the Atmospheric Sciences 27: 1693-1712.

Huang BH, Schopf PS, Pan ZQ. 2002. The ENSO effect on the tropical Atlantic variability: A regionally coupled model study. Geophysical Research Letters 29: 2039, DOI: 10.1029/2002GL014872.

Huang BH, Schopf PS, Shukla J. 2004. Intrinsic ocean-atmosphere variability of the tropical Atlantic Ocean. Journal of Climate 17: $2058-2077$.

Joyce TM, Frankignoul C, Yang JY. 2004. Ocean response and feedback to the SST dipole in the tropical Atlantic. Journal of Physical Oceanography 34: 2525-2540.

Kistler R, Kalnay E, Collins W, Saha S, White G, Woollen J, Chelliah M, Ebisuzaki W, Kanamitsu M, Kousky V, van den Dool H, Jenne R, Fiorino M. 2001. The NCEP-NCAR 50-year reanalysis: Monthly means CD-ROM and documentation. Bulletin of the American Meteorological Society 82: 247-267.

Klein SA, Soden BJ, Lau NC. 1999. Remote sea surface temperature variations during ENSO: Evidence for a tropical atmospheric bridge. Journal of Climate 12: 917-932.

Latif M, Grötzner A. 2000. The equatorial Atlantic oscillation and its response to ENSO. Climate Dynamics 16: $213-218$.

Liebmann B, Smith CA. 1996. Description of a complete (interpolated) outgoing longwave radiation dataset. Bulletin of the American Meteorological Society 77: 1275-1277.

Liu Z, Zhang Q, Wu L. 2004. Remote impact on tropical Atlantic climate variability: statistical assessment and dynamic assessment. Journal of Climate 17: 1529-1549.

Mariotti A, Ballabrera-Poy J, Zeng N. 2005. Tropical influence on Euro-Asian autumn rainfall variability. Climate Dynamics 24: $511-521$.

Matthews AJ, Kiladis GN. 1999. Interactions between ENSO, transient circulation, and tropical convection over the Pacific. Journal of Climate 12: 3062-3086.

Mo KC, Häkkinen S. 2001. Interannual variability in the tropical Atlantic and linkages to the Pacific. Journal of Climate 14: $2740-2762$

Mo KC, Paegle JN. 2001. The Pacific-South American modes and their downstream effects. International Journal of Climatology 21: $1211-1229$.

Philander SGH. 1986. Unstable conditions in the tropical Atlantic ocean in 1984. Nature 322: 236-238.

Pozo-Vazquez D, Esteban-Parra MJ, Rodrigo FS, Castro-Diez Y. 2001. The association between ENSO and winter atmospheric circulation and temperature in the North Atlantic region. Journal of Climate 14: 3408-3420.

Ruiz-Barradas A, Carton JA, Nigam S. 2000. Structure of interannual-to-decadal climate variability in the tropical Atlantic sector. Journal of Climate 13: 3285-3297.

Ruiz-Barradas A, Carton JA, Nigam S. 2003. Role of the Atmosphere in climate variability of the tropical Atlantic. Journal of Climate 16: $2052-2065$.

Saravanan R, Chang P. 2000. Interaction between tropical Atlantic variability and El Niño-Southern Oscillation. Journal of Climate 13: 2177-2194

Servain J, Picaut J, Merle J. 1982. Evidence of remote forcing in the equatorial Atlantic Ocean. Journal of Physical Oceanography 12: 457-463.

Spencer H, Slingo JM. 2003. The simulation of peak and delayed ENSO teleconnections. Journal of Climate 16: 1757-1774.

Sterl A, Hazeleger W. 2003. Coupled variability and air-sea interaction in the South Atlantic Ocean. Climate Dynamics 21: 559-571.

Sutton RT, Jewson SP, Rowell DP. 2000. The elements of climate variability in the tropical Atlantic region. Journal of Climate 13: $3261-3284$.

Tourre YM, Rajagopalan B, Kushnir Y. 1999. Dominant patterns of climate variability in the Atlantic Ocean during the last 136 years. Journal of Climate 12: 2285-2299.

Tseng L, Mechoso CR. 2001. A quasi-biennial oscillation in the equatorial Atlantic Ocean. Geophysical Research Letters 28: 187-190.

Wu L, Zhang Q, Liu Z. 2004. Toward understanding tropical Atlantic variability using coupled modeling surgery. In Earth Climate: The Ocean-Atmosphere Interaction, Wang C, Xie SP, Carton JA (eds). Geophysical Monograph. AGU: Washington, DC. 
Wu AM, Hsieh WW. 2004. The nonlinear association between ENSO and the Euro-Atlantic winter sea level pressure. Climate Dynamics 23: $859-868$.

Xie SP, Carton JA. 2004. Tropical Atlantic variability: Patterns, mechanisms, and impacts. In Earth Climate: The Ocean-Atmosphere Interaction, Wang C, Xie SP, Carton JA (eds). Geophysical Monograph. AGU: Washington, DC.

Xie SP, Philander SGH. 1994. A coupled ocean-atmosphere model of relevance to the ITCZ in the central Pacific. Tellus 46A: 340-350.

Xie SP, Tanimoto Y, Noguchi H, Matsuno T. 1999. How and why climate variability differs between the tropical Atlantic and Pacific. Geophysical Research Letters 26: 1609-1612.

Zebiak SE. 1993. Air-sea interactions in the equatorial Atlantic region. Journal of Climate 6: 1567-1586. 